\title{
Methane retrieved from TROPOMI: improvement of the data product and validation of the first 2 years of measurements
}

\author{
Alba Lorente $^{1}$, Tobias Borsdorff ${ }^{1}$, Andre Butz ${ }^{2,3}$, Otto Hasekamp $^{1}$, Joost aan de Brugh ${ }^{1}$, Andreas Schneider ${ }^{1}$, \\ Lianghai Wu ${ }^{1}$, Frank Hase ${ }^{4}$, Rigel Kivi ${ }^{5}$, Debra Wunch ${ }^{6}$, David F. Pollard ${ }^{7}$, Kei Shiomi ${ }^{8}$, Nicholas M. Deutscher ${ }^{9}$, \\ Voltaire A. Velazco ${ }^{9}$, Coleen M. Roehl ${ }^{10}$, Paul O. Wennberg ${ }^{10}$, Thorsten Warneke ${ }^{11}$, and Jochen Landgraf ${ }^{1}$ \\ ${ }^{1}$ Earth science group, SRON Netherlands Institute for Space Research, Utrecht, the Netherlands \\ ${ }^{2}$ Institute of Environmental Physics, University of Heidelberg, Heidelberg, Germany \\ ${ }^{3}$ Heidelberg Center for the Environment, University of Heidelberg, Heidelberg, Germany \\ ${ }^{4}$ Institute of Meteorology and Climate Research (IMK-ASF), Karlsruhe Institute of Technology, Karlsruhe, Germany \\ ${ }^{5}$ Greenhouse Gases and Satellite Methods group, Finnish Meteorological Institute, Sodankylä, Finland \\ ${ }^{6}$ Department of Physics, University of Toronto, Toronto, Canada \\ ${ }^{7}$ National Institute of Water and Atmospheric Research Ltd (NIWA), Lauder, New Zealand \\ ${ }^{8}$ Japan Aerospace Exploration Agency (JAXA), Tsukuba, Japan \\ ${ }^{9}$ Centre for Atmospheric Chemistry, School of Earth, Atmospheric and Life Sciences, \\ University of Wollongong, Wollongong, NSW 2522, Australia \\ ${ }^{10}$ Division of Geological and Planetary Sciences, California Institute of Technology, Pasadena, California, USA \\ ${ }^{11}$ Institute of Environmental Physics, University of Bremen, Bremen, Germany
}

Correspondence: Alba Lorente (a.lorente.delgado@sron.nl)

Received: 13 July 2020 - Discussion started: 5 August 2020

Revised: 9 November 2020 - Accepted: 24 November 2020 - Published: 28 January 2021

\begin{abstract}
The TROPOspheric Monitoring Instrument (TROPOMI) on board the Sentinel 5 Precursor (S5-P) satellite provides methane $\left(\mathrm{CH}_{4}\right)$ measurements with high accuracy and exceptional temporal and spatial resolution and sampling. TROPOMI $\mathrm{CH}_{4}$ measurements are highly valuable to constrain emissions inventories and for trend analysis, with strict requirements on the data quality. This study describes the improvements that we have implemented to retrieve $\mathrm{CH}_{4}$ from TROPOMI using the RemoTeC full-physics algorithm. The updated retrieval algorithm features a constant regularization scheme of the inversion that stabilizes the retrieval and yields less scatter in the data and includes a higher resolution surface altitude database. We have tested the impact of three state-of-the-art molecular spectroscopic databases (HITRAN 2008, HITRAN 2016 and Scientific Exploitation of Operational Missions - Improved Atmospheric Spectroscopy Databases SEOM-IAS) and found that SEOM-IAS provides the best fitting results. The most relevant update in the TROPOMI $\mathrm{XCH}_{4}$ data product is the implementation of an a posteriori correction fully
\end{abstract}

independent of any reference data that is more accurate and corrects for the underestimation at low surface albedo scenes and the overestimation at high surface albedo scenes. After applying the correction, the albedo dependence is removed to a large extent in the TROPOMI versus satellite (Greenhouse gases Observing SATellite - GOSAT) and TROPOMI versus ground-based observations (Total Carbon Column Observing Network - TCCON) comparison, which is an independent verification of the correction scheme. We validate 2 years of TROPOMI $\mathrm{CH}_{4}$ data that show the good agreement of the updated TROPOMI $\mathrm{CH}_{4}$ with TCCON $(-3.4 \pm 5.6 \mathrm{ppb})$ and GOSAT $(-10.3 \pm 16.8 \mathrm{ppb})$ (mean bias and standard deviation). Low- and high-albedo scenes as well as snow-covered scenes are the most challenging for the $\mathrm{CH}_{4}$ retrieval algorithm, and although the a posteriori correction accounts for most of the bias, there is a need to further investigate the underlying cause. 


\section{Introduction}

Methane $\left(\mathrm{CH}_{4}\right)$ is the second most important anthropogenic greenhouse gas after carbon dioxide $\left(\mathrm{CO}_{2}\right)$. The global warming potential of $\mathrm{CH}_{4}$ for a 20 -year horizon is more than 80 times higher than that of $\mathrm{CO}_{2}$ (Myhre et al., 2013) and, together with its relatively short lifetime of about 10 years, makes it an ideal short-term target for climate change mitigation strategies via reducing $\mathrm{CH}_{4}$ emissions. $\mathrm{CH}_{4}$ has both natural (e.g. wetlands) and anthropogenic sources (e.g. agriculture and waste together with fossil fuels), and globally $60 \%$ of the total emissions are attributed to anthropogenic sources (Saunois et al., 2020). Natural sources are the most uncertain components of the $\mathrm{CH}_{4}$ budget because of their magnitude and variability, which at the same time depend on characteristics that are vulnerable to changes in the state of the Earth's climate. Furthermore, the interpretation of observed $\mathrm{CH}_{4}$ trends is hampered by the uncertainties in the estimates of $\mathrm{CH}_{4}$ emissions (Turner et al., 2019).

Satellite observations of $\mathrm{CH}_{4}$ are highly valuable to constrain emission inventories and for trend analysis, not only at global scale but also at regional and local scales. $\mathrm{CH}_{4}$ measurements from satellite instruments like GOSAT (Greenhouse gases Observing SATellite) have been used to infer $\mathrm{CH}_{4}$ emissions from natural sources (e.g. tropical wetlands Lunt et al., 2019) and anthropogenic sources (e.g. coal mining in China Miller et al., 2019) and also to map emissions and trends at global scale (e.g. Maasakkers et al., 2019). However, the spatial and temporal resolution at which these emissions can be resolved are limited by the capabilities of the instrument, preventing daily estimations or source attribution at fine scales.

A unique perspective for the long-term monitoring of $\mathrm{CH}_{4}$ is provided by the TROPOMI (TROPOspheric Monitoring Instrument) instrument on board the Sentinel 5 Precursor (S5-P) satellite, with its daily global coverage at an unprecedented resolution of $7 \times 7 \mathrm{~km}^{2}$ since its launch in October 2017 (upgraded to $5.5 \times 7 \mathrm{~km}^{2}$ in August 2019). The high resolution together with the high signal-to-noise ratio allows for the detection and quantification of $\mathrm{CH}_{4}$ emissions from localized (e.g. Pandey et al., 2019) to larger scale sources (e.g. Permian basin by Schneising et al., 2020; Zhang et al., 2020). Furthermore, assimilating TROPOMI $\mathrm{CH}_{4}$ has shown great potential (e.g. in the Copernicus Atmosphere Monitoring Service (CAMS) ECMWF Integrated Forecasting System (CAMS-IFS) data assimilation system; Barré et al., 2020). The main challenge of $\mathrm{CH}_{4}$ remote sensing is that high data quality is required for data assimilation and flux inversion applications. For TROPOMI, strict mission requirements are formulated, with a single sounding precision and accuracy both below $1 \%$ (Veefkind et al., 2012).

TROPOMI $\mathrm{CH}_{4}$ operational data were already proved to be of good quality by comparisons shortly after launch with both GOSAT observations (Hu et al., 2018) and groundbased measurements from the Total Carbon Column Observ- ing Network (TCCON; Hasekamp et al., 2019). However, the $\mathrm{CH}_{4}$ data product can now be further improved using real measurements after TROPOMI has been measuring for more than 2 years. A detailed analysis of the data provides insight into which aspects of the processing chain regarding the input data or retrieval algorithm can be further improved. The long-term record also allows us to explore possibilities of correcting biases independent of any reference data (e.g. ground-based or other satellite measurements).

In this study we present the improvements that we have developed to retrieve $\mathrm{CH}_{4}$ from TROPOMI measurements using the full-physics approach, and we validate the TROPOMI $\mathrm{CH}_{4}$ product with satellite and ground-based measurements. Section 2 describes the data and analysis methods that we use, and Sect. 3 focuses on the main improvements related to the regularization scheme of the inversion, the choice of the spectroscopic database for the absorption cross-sections, the surface elevation database and an a posteriori bias correction derived using only TROPOMI data. Finally, Sects. 4 and 5 show a detailed validation of the improved TROPOMI $\mathrm{CH}_{4}$ data. The study concludes in Sect. 6, with an outlook for future steps regarding $\mathrm{CH}_{4}$ data retrieved from TROPOMI.

\section{Retrieval algorithm and validation datasets}

\subsection{TROPOMI $\mathrm{CH}_{4}$ retrieval algorithm}

The methane total column-averaged dry-air mole fraction $\left(\mathrm{XCH}_{4}\right)$ is retrieved from TROPOMI measurements of sunlight backscattered by Earth's surface and atmosphere in the near-infrared (NIR) and shortwave-infrared (SWIR) spectral bands with the retrieval algorithm RemoTeC. This algorithm has been extensively used to retrieve both $\mathrm{CO}_{2}$ and $\mathrm{CH}_{4}$ from measurements of OCO-2 and GOSAT (e.g. Wu et al., 2018; Butz et al., 2011), and it is the Sentinel 5-P and Sentinel 5 operational algorithm for $\mathrm{CH}_{4}$ (Hasekamp et al., 2019; Landgraf et al., 2019).

The S5P RemoTeC algorithm uses the full-physics approach that simultaneously retrieves the amount of atmospheric $\mathrm{CH}_{4}$ and the physical scattering properties of the atmosphere. The algorithm aims at inferring the state vector $\boldsymbol{x}$ that contains all the parameters to be retrieved from the radiance measurements $\boldsymbol{y}$ in the SWIR $(2305-2385 \mathrm{~nm})$ and NIR (757-774 nm) spectral bands, where the forward model $\boldsymbol{F}$ simulates the TROPOMI measurements,

$\boldsymbol{y}=\boldsymbol{F}(\boldsymbol{x})+\epsilon_{y}+\epsilon_{F}$.

Here, $\epsilon_{y}$ and $\epsilon_{F}$ are the measurement noise error and the forward model error respectively. The forward model employs the LINTRAN V2.0 radiative transfer model in its scalar approximation to simulate atmospheric light scattering and absorption in a plane parallel atmosphere (Schepers et al., 2014; Landgraf et al., 2001). Accurate modelling of absorption by molecules relies on spectroscopic databases, 
which provide the absorption cross-section of the target absorber $\mathrm{CH}_{4}$ as well as of the interfering gases $\mathrm{CO}, \mathrm{H}_{2} \mathrm{O}$ and $\mathrm{O}_{2}$.

The inversion to estimate the state vector $\boldsymbol{x}$ requires the use of regularization methods, as measurements typically do not contain sufficient information to retrieve every state vector element independently. The RemoTeC retrieval algorithm uses the Philips-Tikhonov regularization scheme, which aims to find the state vector by solving the minimization problem

$\hat{\boldsymbol{x}}=\min \left(\left\|\mathbf{S}_{y}^{-1 / 2}(\boldsymbol{F}(x)-\boldsymbol{y})\right\|^{2}+\gamma\left\|\mathbf{W}\left(\boldsymbol{x}-\boldsymbol{x}_{a}\right)\right\|^{2}\right)$,

where $\|\cdot\|$ describes the Euclidian norm, $\mathbf{S}_{y}$ is the measurement error covariance matrix that contains the noise estimate, $\gamma$ is the regularization parameter, $\mathbf{W}$ is a diagonal weighting matrix that renders the side constraint dimensionless and ensures that only the target absorber $\mathrm{CH}_{4}$ and the scattering parameters contribute to its norm (Hu et al., 2016) and $\boldsymbol{x}_{a}$ is the a priori state vector.

The retrieval state vector contains $\mathrm{CH}_{4}$ partial sub-column number densities at 12 equidistant pressure layers. The total columns of the interfering non-target absorbers $\mathrm{CO}$ and $\mathrm{H}_{2} \mathrm{O}$ are also retrieved, together with the effective aerosol total column, size and height parameter of the aerosol power law distribution. A Lambertian surface albedo in both the NIR and SWIR spectral range together with its first-order spectral dependence is also retrieved, as well as spectral shift and fluorescence in the NIR band.

The TROPOMI $\mathrm{CH}_{4}$ data product is given in the form of total column-averaged dry-air mole fraction, $\mathrm{XCH}_{4}$. It is calculated from the methane vertical sub-column elements $x_{i}$ and the dry-air column $V_{\text {air,dry }}$ calculated with meteorology input from ECMWF (European Centre for Medium-Range Weather Forecasts) operational analysis product and surface topography from a high-resolution database:

$\mathrm{XCH}_{4}=\sum_{i=0}^{n} \frac{x_{i}}{V_{\text {air, dry }}}$.

The precision $\sigma_{\mathrm{XCH}_{4}}$ available in the data product is defined as the standard deviation of the retrieval noise, which follows from the error covariance matrix $\mathbf{S}_{x}$ that describes the effect of the measurement noise on the retrieval (Hu et al., 2016):

$\sigma_{\mathrm{XCH}_{4}}=\frac{\sqrt{\sum_{i, j=0}^{n} S_{x, i, j}}}{V_{\text {air,dry }}}$.

The algorithm has been designed to provide accurate and precise retrievals for clear-sky scenes with minor scattering by aerosols and optically thin cirrus. To fulfil this criterion, a strict cloud filter is applied based on observations of the Visible Infrared Imaging Radiometer Suite (VIIRS) aboard the Suomi-NPP satellite that observes the same scene as
TROPOMI approximately 5 min earlier. In fewer than $1 \%$ of the cases when VIIRS data are not available, we use a backup filter based on a non-scattering $\mathrm{H}_{2} \mathrm{O}$ and $\mathrm{CH}_{4}$ retrieval from the weak and strong absorption bands (Hu et al., 2016). These cases are flagged accordingly by the quality value indicator. Table A1 summarizes the filters applied in the retrieval process and in the TROPOMI data selection used in this study.

The $\mathrm{CH}_{4}$ total column-averaged dry-air mole fraction retrieved from TROPOMI with the operational retrieval algorithm (version 1.2.0) largely complies with the mission requirement of precision and accuracy below $1 \%$, with significantly improved data quality of the bias-corrected product (Hasekamp et al., 2019). In Sect. 3 we present recent updates that further improve the quality of the data. The TROPOMI $\mathrm{XCH}_{4}$ scientific data product from SRON retrieved with the updated algorithm serves as a beta version of the operational processing. Another scientific retrieval algorithm using the weighting function modified differential optical absorption spectroscopy (WFM-DOAS) method to retrieve $\mathrm{CO}$ and $\mathrm{CH}_{4}$ from TROPOMI was presented by Schneising et al. (2019). Comparison of both retrieval approaches is foreseen as part of ongoing verification activities.

\subsection{TCCON reference dataset}

To validate $\mathrm{XCH}_{4}$ retrieved from TROPOMI we use independent ground-based $\mathrm{XCH}_{4}$ measurements from the Total Carbon Column Observing Network (TCCON) (Wunch et al., 2011a) as a reference (data version GGG2014). Table 1 contains the information of the 13 different stations located in North America, East Asia, Europe and Oceania used for the validation. In regions where there are multiple TCCON stations, we have selected those located at flat terrain in relatively remote areas, which minimizes the errors due to assumptions on the vertical $\mathrm{CH}_{4}$ distribution used to correct for differences between the surface elevation of TROPOMI particular pixels and the ground altitude at the TCCON sites.

To evaluate the quality of the retrieved TROPOMI $\mathrm{XCH}_{4}$, we average TROPOMI $\mathrm{XCH}_{4}$ data within a collocation radius around each station of $300 \mathrm{~km}$. The average retrieved TROPOMI $\mathrm{XCH}_{4}$ within the specific radius is compared with measurements of the matching TCCON station within $\pm 2 \mathrm{~h}$ of the TROPOMI overpass $\left(\mathrm{XCH}_{4, \mathrm{TROPOMI}}-\right.$ $\mathrm{XCH}_{4, \mathrm{TCCON}}$ ). For all paired collocations at each station, we compute the mean bias defined as the mean of the difference of individual collocations $\left(\Delta \mathrm{CH}_{4}\right)$ and its standard deviation $(\sigma)$ as a measure of the spread in the data. We then compute the average of the station biases $(\bar{b})$ and its standard deviation $(\sigma(\bar{b}))$ as a measure of the station-to-station variability. The station-to-station variability is an important diagnostic parameter as it indicates regional biases in our data, and it might be used as an overall uncertainty estimate. 
Table 1. Overview of the stations from TCCON used in this study.

\begin{tabular}{lrrl}
\hline Site (country) & Coordinates lat., long. $\left(^{\circ}\right)$ & Altitude (m a.s.l.) & Reference \\
\hline Sodankylä (Finland) & $67.37,26.63$ & 190 & Kivi and Heikkinen (2016), Kivi et al. (2017) \\
East Trout Lake (Canada) & $54.36,-104.99$ & 500 & Wunch et al. (2017) \\
Karlsruhe (Germany) & $49.1,8.44$ & 110 & Hase et al. (2017) \\
Orléans (France) & $47.97,2.11$ & 130 & Warneke et al. (2017) \\
Park Falls (USA) & $45.94,-90.27$ & 440 & Wennberg et al. (2017a) \\
Lamont (USA) & $36.6,-97.49$ & 320 & Wennberg et al. (2017b) \\
Pasadena (USA) & $34.14,-118.13$ & 240 & Wennberg et al. (2017c) \\
Edwards (USA) & $34.95,-117.88$ & 30 & Iraci et al. (2016) \\
Saga (Japan) & $33.24,130.29$ & 10 & Kawakami et al. (2017) \\
Darwin (Australia) & $-12.46,130.93$ & 30 & Griffith et al. (2017a) \\
Wollongong (Australia) & $-34.41,150.88$ & 30 & Griffith et al. (2017b) \\
Lauder* (New Zealand) & $-45.04,169.68$ & 370 & Sherlock et al. (2017), Pollard et al. (2019) \\
\hline
\end{tabular}

* For the Lauder station, the 11 instrument was replaced on October 2018 by the $1 r$ instrument.

\subsection{GOSAT reference dataset}

$\mathrm{XCH}_{4}$ measurements by the Thermal and Near Infrared Sensor for Carbon Observation Fourier transform spectrometer (TANSO-FTS) on board the Greenhouse gases Observing SATellite (GOSAT) satellite are used for the validation of the TROPOMI $\mathrm{XCH}_{4}$ data. GOSAT was launched in 2009, and it performs three-point observations in a cross-track swath of $790 \mathrm{~km}$ with $10.5 \mathrm{~km}$ resolution on the ground at nadir, which results in global coverage approximately every $3 \mathrm{~d}$.

We use the GOSAT proxy $\mathrm{XCH}_{4}$ data product produced at SRON in the context of the ESA GreenHouse Gas Climate Change Initiative (GHG CCI) project (Buchwitz et al., 2019, 2017). This $\mathrm{XCH}_{4}$ product is retrieved using the RemoTeC/proxy retrieval algorithm. The proxy approach (Frankenberg et al., 2005) infers a $\mathrm{CO}_{2}$ and $\mathrm{CH}_{4}$ total column from observations at $1.6 \mu \mathrm{m}$, ignoring any atmospheric scattering in the retrieval. Substantially, the $\mathrm{XCH}_{4}$ product is derived by

$\mathrm{XCH}_{4}{ }^{\text {proxy }}=\frac{V_{\mathrm{CH}_{4}}}{V_{\mathrm{CO}_{2}}} \cdot \mathrm{XCO}_{2}{ }^{\text {mod }}$,

where the column-averaged dry-air mole fraction $\mathrm{XCO}_{2}$ mod is taken from the Carbon Tracker data assimilation system, and $V_{\mathrm{CH}_{4}}$ and $V_{\mathrm{CO}_{2}}$ are the vertical column densities. This approach assumes that light path modifications due to scattering in the atmosphere are the same for the target absorber (i.e. $\mathrm{CH}_{4}$ ) and the proxy absorber $\mathrm{CO}_{2}$, whose prior is assumed to be known with high accuracy.

In the validation in Sect. 5 we found that there is no bias between the GOSAT proxy and full-physics products. However, for the comparison we have selected the GOSAT proxy product over the full-physics because of its higher data yield. The proxy approach cannot be applied to retrieve $\mathrm{XCH}_{4}$ from TROPOMI since it does not cover the $1.6 \mu \mathrm{m} \mathrm{CH}_{4}$ and $\mathrm{CO}_{2}$ absorption bands. Schepers et al. (2012) compared both the physics and proxy retrievals applied to GOSAT measure- ments to retrieve $\mathrm{XCH}_{4}$ and concluded that both retrievals performed similarly with respect to bias variability and precision when validating the retrieved $\mathrm{XCH}_{4}$ with ground-based TCCON measurements. This study also concluded that both methods can retrieve $\mathrm{XCH}_{4}$ in aerosol-loaded scenes with retrieval errors of less than $1 \%$.

\section{TROPOMI $\mathrm{CH}_{4}$ retrieval updates}

The TROPOMI $\mathrm{XCH}_{4}$ scientific data product from SRON retrieved with the updated algorithm will be suggested for use in the operational processing in the next processor update. The updates to the S5P-RemoTeC retrieval algorithm relate to the regularization scheme, the selection of the spectroscopic database, the implementation of a higher resolution digital elevation map (DEM) for surface altitude and a more sophisticated a posteriori correction for the albedo dependence. In this section we present the updates and quantify the improvements, and we use the comparison with TCCON and GOSAT as a benchmark to test the performance of the retrieval after implementing the updates.

\subsection{Regularization scheme}

$\mathrm{Hu}$ et al. (2016) determined the regularization parameter $\gamma$ in the inversion (Eq. 2) using the L-curve criterion (Hansen, 1998; Hu et al., 2016) in each iteration of the TROPOMI measurement inversion. As TROPOMI has been measuring for more than 2 years, it is possible to select a constant regularization optimized for real observations. This includes a dedicated regularization parameter for the target absorber $\mathrm{CH}_{4}$ and one for each of the scattering parameters (effective aerosol distribution height and size parameter, and effective aerosol column). The advantage of the constant regularization is a more stable performance compared to the L-curve method in which the regularization strength changes at each iteration for every scene. The regularization parameters are 
selected such that the degrees of freedom for $\mathrm{CH}_{4}$ are between 1 and 1.5 and that retrieved scattering parameters follow a distribution that we would expect.

The main improvement of the constant regularization is that the dispersion in the retrieved $\mathrm{XCH}_{4}$ is significantly reduced. This is noticeable in the $\mathrm{XCH}_{4}$ distribution over small regions where we do not expect large gradients of $\mathrm{XCH}_{4}$. At regions with relatively low albedo, the decrease in the spread of the data can reach $10 \%-20 \%$ (e.g. from 18 to $14 \mathrm{ppb}$ over Canada and 11 to 9 over Australia). Furthermore, the validation with TCCON shows a decrease in the station-to-station variability of $4 \mathrm{ppb}(25 \%$ decrease of the $15 \mathrm{ppb}$ station-to-station variability using the L-curve approach) when analysing 1 year of data. The comparison with GOSAT shows that the new regularization scheme reduces the standard deviation of the difference between collocated GOSAT and TROPOMI $\mathrm{XCH}_{4}$ observations by $9 \%$ (from 21.5 to $19.7 \mathrm{ppb})$.

\subsection{Spectroscopy database}

The TROPOMI $\mathrm{CH}_{4}$ retrieval uses external spectroscopic information to simulate the molecular absorption lines of the target absorber $\mathrm{CH}_{4}$ as well as of $\mathrm{CO}$ and $\mathrm{H}_{2} \mathrm{O}$. The baseline retrieval algorithm employs the HITRAN 2008 spectroscopic database (Rothman et al., 2009) with updated spectroscopy parameters for $\mathrm{H}_{2} \mathrm{O}$ from Scheepmaker et al. (2013). In preparation for the Sentinel 5 Precursor mission, Birk et al. (2017) established an improved spectroscopic database, the so-called Scientific Exploitation of Operational Missions - Improved Atmospheric Spectroscopy Databases (SEOMIAS hereafter) for the interpretation of TROPOMI observations. The release of the HITRAN 2016 database already included some of the updates from the SEOM-IAS project regarding $\mathrm{H}_{2} \mathrm{O}$ (Gordon et al., 2017). We have tested the effect of the three spectroscopic databases on the retrieved $\mathrm{XCH}_{4}$ using 1 year of TROPOMI data (September 2018-September 2019).

The TCCON validation shows that after substituting HITRAN 2008 by HITRAN 2016 and SEOM-IAS for all the molecules in the $\mathrm{CH}_{4}$ retrieval, the station-to-station variability does not change significantly (less than $1 \mathrm{ppb}$; see Table 2). The change in the mean bias shows that the different spectroscopy databases introduce an overall bias in the retrieved $\mathrm{XCH}_{4}$ with respect to HITRAN $2008(+20.3 \mathrm{ppb}$ for HITRAN 2016 and $-14.7 \mathrm{ppb}$ for SEOM-IAS), but the correlation of the bias with other retrieved parameters (surface albedo, $\mathrm{H}_{2} \mathrm{O}$ ) does not improve or worsen with any of the spectroscopic database. The spectral fitting quality parameters (e.g. the root mean square of the spectral fit residuals, rms, and the corresponding $\chi^{2}$ ) show a slight improvement over TCCON stations when using the SEOM-IAS spectroscopic database, similar to what was found for the $\mathrm{CO}$ retrieval from TROPOMI (Borsdorff et al., 2019). The comparison with $\mathrm{XCH}_{4}$ measured by GOSAT also shows that differ-

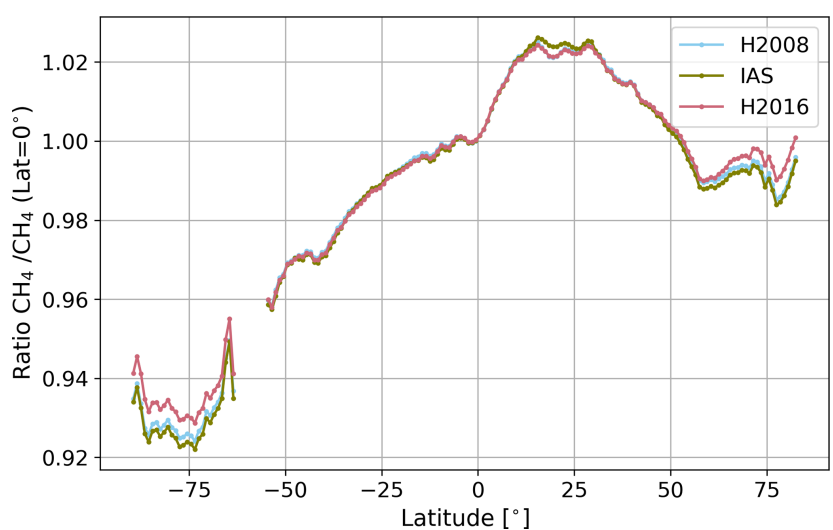

Figure 1. Latitudinal distribution of TROPOMI $\mathrm{XCH}_{4}$ retrieved using HITRAN 2008 (blue), HITRAN 2016 (pink) and SEOMIAS (green), referenced to the value at $0^{\circ}$ latitude. Daily measurements from September 2018-September 2019 are gridded into a $0.2^{\circ} \times 0.2^{\circ}$ grid, averaged longitudinally and then binned in $1^{\circ}$ latitude.

ent spectroscopic databases introduce an overall bias, but the standard deviation of the bias does not change significantly (Table 2).

On a global scale, we see that both the rms and $\chi^{2}$ improve significantly when using the SEOM-IAS database, with HITRAN 2008 giving the worst fitting results. Global mean $\chi^{2}$ improves by $19 \%$ with SEOM-IAS cross-section and by $7 \%$ with HITRAN 2016 with respect to HITRAN 2008. Figure 1 shows the latitudinal distribution of $\mathrm{XCH}_{4}$ retrieved with $\mathrm{HI}-$ TRAN 2008, SEOM-IAS and HITRAN 2016, referenced to the value at $0^{\circ}$ latitude. $\mathrm{XCH}_{4}$ retrieved with HITRAN 2016 shows the least latitudinal variation at latitudes higher than $55^{\circ}$ where differences between the datasets are largest; however the global distribution does not point to a better performance of any of the spectroscopic databases. The validation with TCCON observations including Eureka $\left(80.05^{\circ} \mathrm{N}\right)$ and Lauder $\left(45.04^{\circ} \mathrm{S}\right)$ just reflects the overall bias but does not point to any latitudinal bias of $\mathrm{XCH}_{4}$ retrieved with any of the spectroscopic databases (not shown).

The results of the sensitivity tests do not point to an improved data quality when the HITRAN 2016, SEOM-IAS or HITRAN 2008 spectroscopic database is used. Each of them introduces an overall bias that cannot be used as an independent argument to favour a specific database. In view of the better spectral fitting results in the retrieved $\mathrm{XCH}_{4}$, we have decided to use the SEOM-IAS spectroscopy database.

\subsection{Surface elevation}

Satellite remote sensing of $\mathrm{XCH}_{4}$ requires accurate knowledge of surface pressure and thus of surface elevation, which is specially relevant for the spatially highly resolved measurements of TROPOMI. The effect is twofold: (1) through the pressure dependence of the absorption cross-sections and 
Table 2. Overview of the TCCON and GOSAT validation results (mean bias and its standard deviation) for the TROPOMI $\mathrm{XCH}_{4}$ retrieved with different spectroscopic databases.

\begin{tabular}{lr}
\hline & $\bar{b} \pm \sigma(\bar{b}) \mathrm{CH}_{4}(\mathrm{ppb})^{*}$ \\
\hline TCCON & \\
\hline HITRAN 2008 & $-2.4 \pm 11.7$ \\
SEOM-IAS & $-17.1 \pm 12.4$ \\
IHITRAN 2016 & \\
\hline GOSAT & $3.9 \pm 11.1$ \\
\hline HITRAN 2008 & $-8.4 \pm 22.8$ \\
SEOM-IAS & $23.8 \pm 19.7$ \\
HITRAN 2016
\end{tabular}

$* b=$ TROPOMI - ref

(2) through the dry-air column used to calculate the dry-air mixing ratio from the retrieved column (Eq. 3).

In a first preprocessing step of the retrieval, the elevation data from a digital elevation map (DEM) are interpolated in space to the ground pixel. Then a correction is applied to the atmospheric variables (i.e. surface pressure and model pressure levels) based on the difference between the coarse resolution ECMWF altitude and the surface elevation from the DEM. To minimize errors, a filter is applied on terrain roughness, which excludes scenes with a standard deviation of the surface elevation higher than $80 \mathrm{~m}$ within the observed area. The default source for surface elevation information for all TROPOMI products is the Global multi-resolution terrain elevation data 2010 DEM (GMTED2010), with an aggregation radius of $5 \mathrm{~km}$ and a sampling of around $2 \mathrm{~km}$, which results in a resolution of approximately $2 \mathrm{~km}$ (S5P-DEM hereafter).

The updated retrieval scheme uses the Shuttle Radar Topography Mission (SRTM) (Farr et al., 2007) digital elevation map with a resolution of 15 arcsec, approximately $400 \mathrm{~m}$. To match the DEM surface elevation with the ground pixel, we perform a spatial sampling of $0.5 \mathrm{~km}$ and compute the mean altitude and its standard deviation for each scene. Figure 2a shows altitude differences between S5PDEM and SRTM collocated to TROPOMI pixels (before altitude correction) on 5 May 2019 over the United States. In this specific area, $5 \%$ of the pixels have differences in altitude greater than $45 \mathrm{~m}$, with the highest differences over mountain regions. For these scenes the differences in retrieved $\mathrm{XCH}_{4}$ are up to $7 \mathrm{ppb}$. On a yearly average (and after correction and quality filtering), $1 \%$ of the retrievals present altitude differences greater than $50 \mathrm{~m}$, which result in surface pressure differences above $5 \mathrm{hPa}$ and $\mathrm{XCH}_{4}$ differences above $10 \mathrm{ppb}$ (Fig. 2b-d). The terrain roughness within TROPOMI pixels has not changed significantly with the SRTM DEM, so it does not affect the data yield due to the $80 \mathrm{~m}$ threshold. Although globally the average altitude difference is small, the analysis of small-scale $\mathrm{XCH}_{4}$ enhancements will bene- fit from this update. Due to its higher resolution, the SRTM DEM is a better representation of elevation not only over mountains, but also close to coastlines and over rough terrain (e.g. Greenland, Sahara).

\subsection{Posteriori correction}

Greenhouse gas concentrations retrieved from satellite instruments like TROPOMI generally show systematic biases with different instrumental or geophysical parameters. Retrieved $\mathrm{CO}_{2}$ and $\mathrm{CH}_{4}$ from GOSAT and OCO-2 are typically corrected for dependencies on goodness of fit, surface albedo or aerosol parameters (e.g. Guerlet et al., 2013; Inoue et al., 2016; Wu et al., 2018). In the approach that O'Dell et al. (2018) derived for OCO-2 $\mathrm{CO}_{2}$ retrievals, such parametric bias is part of a more complex correction that also accounts for footprint-level and global biases using a set of four "truth proxies" as a reference.

The comparison of TROPOMI and TCCON $\mathrm{XCH}_{4}$ measurements shows a dependence of the bias (i.e. difference between TROPOMI and TCCON) on surface albedo retrieved in the SWIR spectral range, while for the other retrieved parameters the dependence is negligible (compared to that of the surface albedo; see Fig. 3 with solar zenith angle and aerosol optical depth as an example). Figure 3 a shows that for low-albedo values, TROPOMI $\mathrm{XCH}_{4}$ strongly underestimates TCCON measurements, while for relatively highalbedo values TROPOMI overestimates TCCON measurements. The comparison of TROPOMI $\mathrm{XCH}_{4}$ with $\mathrm{XCH}_{4}$ retrieved from measurements of GOSAT shows the same dependence of the bias with the retrieved surface albedo. For scenes with low-albedo values, generally the retrieval's sensitivity is low due to the large measurement noise, therefore errors from unaccounted light path modification due to scattering processes can be more significant than for scenes with a relatively higher albedo. For low-albedo scenes, this effect leads to an underestimation in the retrieved trace gas (Guerlet et al., 2013; Aben et al., 2007), resembling the TROPOMI $\mathrm{XCH}_{4}$ underestimation in Fig. 3a.

To account for the albedo dependence, we apply an a posteriori bias correction to the retrieved $\mathrm{XCH}_{4}$. In the baseline operational algorithm a few months after TROPOMI was operational, we applied a correction based on the comparison of TROPOMI XCH $\mathrm{X}_{4}$ with GOSAT retrievals (Hasekamp et al., 2019). After more than 2 years of measurements, we have sufficient data to derive a new correction using only TROPOMI $\mathrm{XCH}_{4}$ measurements. We use a similar approach to the "small area approximation" applied to OCO-2 (O'Dell et al., 2018), assuming a uniform $\mathrm{XCH}_{4}$ distribution as a function of albedo in several regions. This approach makes the correction completely independent of any reference data (e.g. GOSAT, TCCON) that could introduce additional biases when applying the correction and does not allow for an independent verification of the correction. 

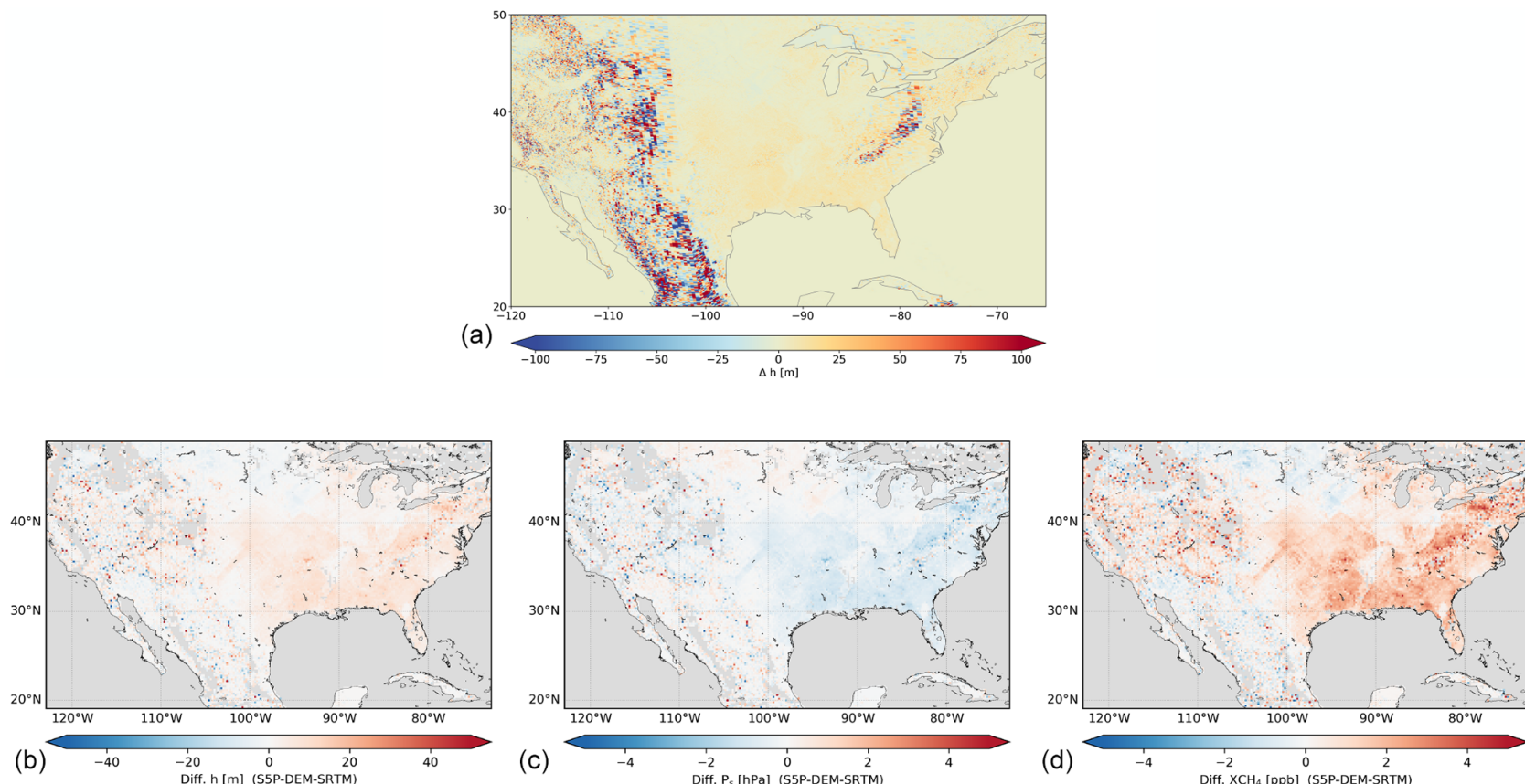

Figure 2. (a) Altitude difference between S5P-DEM and SRTM collocated to TROPOMI pixels on 5 May 2019 (orbits 8077, 8078, 8079). (b-d) Altitude, surface pressure and $\mathrm{XCH}_{4}$ differences averaged over a year, with custom quality filtering for the $\mathrm{TROPOMI} \mathrm{XCH}_{4}$ retrievals, in a $0.2^{\circ} \times 0.2^{\circ}$ grid over the United States $\left(20-50^{\circ} \mathrm{N}, 65-120^{\circ} \mathrm{W}\right)$.
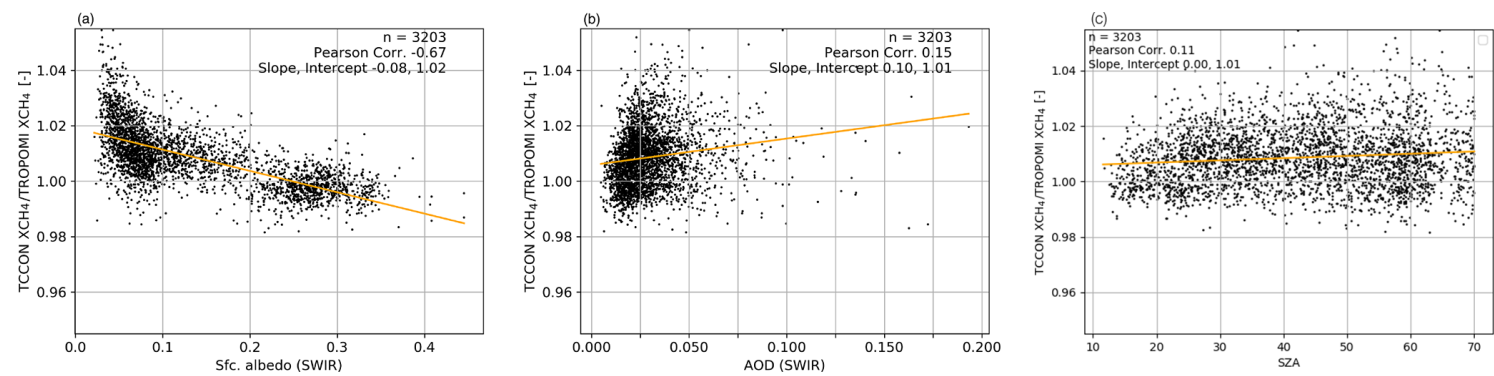

Figure 3. Ratio of $\mathrm{XCH}_{4}$ measurements by TCCON and TROPOMI as a function of (a) retrieved surface albedo in the SWIR spectral range, (b) retrieved effective aerosol optical depth (AOD) in the SWIR spectral range and (c) solar zenith angle (SZA).

The new correction is derived as follows:

1. We select areas at several latitudes and longitudes throughout the globe, small enough so we can assume that $\mathrm{XCH}_{4}$ does not vary but large enough to cover scenes with a wide range of albedo values. Figure B1 shows the different regions.

2. For each region we estimate a $\mathrm{XCH}_{4}$ reference value for a surface albedo around 0.2 , and then we calculate the ratio of the retrieved $\mathrm{XCH}_{4}$ to the reference value to obtain the albedo dependence. The specific value for surface albedo is selected because $\mathrm{XCH}_{4}$ retrieval errors are lower in the SWIR for that albedo range: errors because of unaccounted light path modifications due to scattering and surface albedo are minimal around a sur- face albedo of 0.2 (e.g. Guerlet et al., 2013; Aben et al., 2007).

3. We combine the albedo dependence for all the areas, we fit the curve using B-spline interpolation and leastsquares fitting.

The B-spline method fits piece-wise polynomials that are continuous at the preselected knots. The knots and the order of the polynomials are chosen such that the residual rms of fit residuals is minimum and that the shape of the fit at the edges of the surface albedo range does not vary sharply.

Figure 4 shows the distribution of the reference to TROPOMI $\mathrm{XCH}_{4}$ ratio for all the areas and the result of the B-spline fit. We observe two distinct features: (1) the strong underestimation for low-albedo values (already shown in the TCCON comparison in Fig. 3a), for which the B-spline fit 


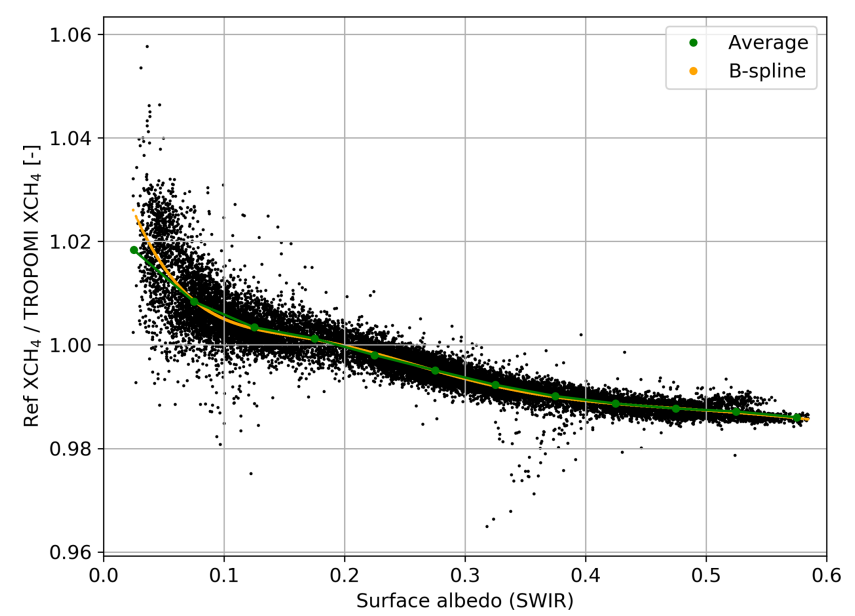

Figure 4. Ratio of reference $\mathrm{XCH}_{4}$ to TROPOMI $\mathrm{XCH}_{4}$ as a function of the retrieved surface albedo as explained in step 3 in the derivation of the bias correction. Green dots show the average ratio in 0.05 albedo bins, and the orange line shows the B-spline fit used to derive the bias correction. Data are averaged from 1 January 2018 until 31 December 2019 in a $0.1^{\circ} \times 0.1^{\circ}$ grid.

corrects more strongly than the regular polynomial fit that was previously derived for the operational product and (2) an overestimation for high-albedo values, not captured by TC$\mathrm{CON}$ due to the limited albedo range values but reported in the TROPOMI and GOSAT comparisons.

The correction applied to the retrieved $\mathrm{XCH}_{4}$ can be expressed as

$\mathrm{XCH}_{4 i}^{\text {corr }}=\mathrm{XCH}_{4 i} \cdot f\left(A_{\mathrm{s} i}\right)$.

The correction function $f$ depends on the retrieved surface albedo $A_{\mathrm{S}}$ in the SWIR spectral range at each pixel $i$.

Figure 5 shows the global distribution of $\mathrm{XCH}_{4}$ before and after applying the correction. Distinctive features that correspond with low and high surface albedo areas are visible in the difference map. After correction, for example, the $\mathrm{XCH}_{4}$ underestimation for low-albedo values (e.g. over high latitudes over Canada and Russia) is corrected. Similarly, the $\mathrm{XCH}_{4}$ overestimation for high-albedo values over desert areas like Sahara is accounted for in the correction. The change in $\mathrm{XCH}_{4}$ induced by the bias correction is in the range of $2 \%$, in agreement with the errors observed in the TCCON comparison.

As the correction is derived using only TROPOMI $\mathrm{XCH}_{4}$ data, the comparison with TCCON and GOSAT is an independent verification of the approach. The validation with TCCON shows a reduction of $5.9 \mathrm{ppb}(50 \%)$ in the stationto-station variability and of $13.6 \mathrm{ppb}$ in the bias due to the albedo correction. The dependence of the bias on surface albedo is removed (Fig. 3a vs. Fig. 6a), and the dependence on other parameters remains negligible (not shown). The comparison with GOSAT measurements shows that bias dependence on albedo is removed after applying the correction
(Fig. 6b), which reduces by $4 \mathrm{ppb}$ the scatter of the differences in $\mathrm{XCH}_{4}$ measured by the two satellites. In the remainder of the paper, the corrected $\mathrm{XCH}_{4}$ product will be used.

\section{Comparison of TROPOMI and TCCON}

\subsection{TCCON validation}

We perform a detailed comparison of the TROPOMI $\mathrm{XCH}_{4}$ corrected with $\mathrm{XCH}_{4}$ measured at 13 TCCON stations selected for the validation (Table 1). TROPOMI is able to capture the temporal $\mathrm{XCH}_{4}$ variability, both the seasonal cycle and the year-to-year increase. This is clearly visible in the time series (e.g. Pasadena or Lamont) in Fig. 7, which shows the time series of daily average $\mathrm{XCH}_{4}$ measured at each TCCON station and by TROPOMI for the period 1 December 2018-31 December 2019, with a collocation radius of $300 \mathrm{~km}$.

The mean bias is below $1 \%$ for all stations; the validation results are summarized in Table 3 . The average bias for all stations is $-0.2 \%(-3.4 \mathrm{ppb})$, and the station-to-station variability is $0.3 \%$ ( $5.6 \mathrm{ppb})$, both parameters below the mission requirements for TROPOMI $\mathrm{XCH}_{4}$ retrievals. Compared to the uncorrected TROPOMI $\mathrm{XCH}_{4}$, the mean bias is reduced significantly (from $-3.4 \%$ to $0.2 \%$ ), even though the correction approach does not include any term to correct a global bias. As the overall negative bias is driven by the strong $\mathrm{XCH}_{4}$ underestimation for low-albedo values (Fig. 3a), correcting for the albedo bias partly accounts for the overall bias.

Figure 8a shows the mean bias and the standard deviation for each of the stations ,and Fig. 8b shows the correlation plot. For a more strict collocation criterion of $100 \mathrm{~km}$ radius instead of $300 \mathrm{~km}$, the number of points is reduced significantly, but the results of the validation do not change.

\subsection{High-latitude stations}

Measurements at high-latitude stations such as East Trout Lake $\left(54.36^{\circ} \mathrm{N}\right)$ and Sodankylä $\left(67.37^{\circ} \mathrm{N}\right)$ show the highest variability and the highest bias in the validation before correction, which is partially reduced by the albedo correction (see validation results in Table 3). There is a seasonality in the bias which is positive during the February-April period and changes to a negative bias around May, that then increases to reach the highest (negative) values in autumn. This seasonality can be attributed to the fact that during the winter there is snow in these regions at high latitudes as a result of cold, dry air, influencing $\mathrm{XCH}_{4}$ measurements by TROPOMI that affect the validation with TCCON measurements.

Figure 9 shows the time series of the bias between TROPOMI and TCCON $\mathrm{XCH}_{4}$, together with the surface albedo retrieved in both the SWIR and NIR spectral range over East Trout Lake, Sodankylä and Lamont, the latter included as a mid-latitude reference. Low surface albedo in 


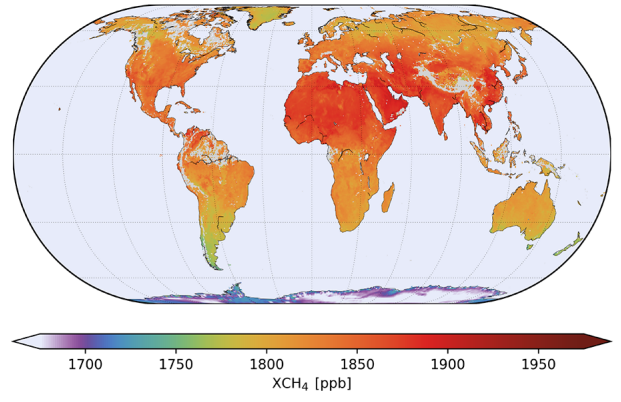

(a)

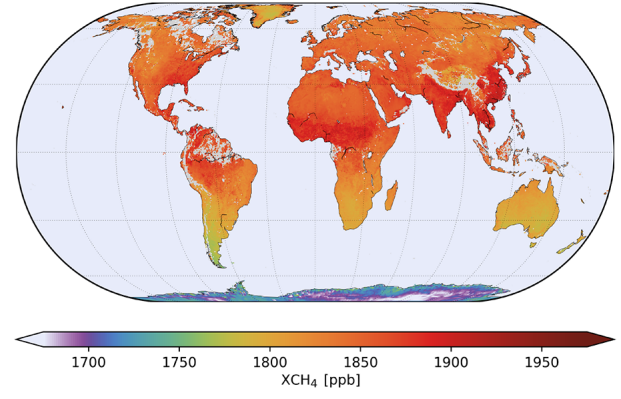

(b)

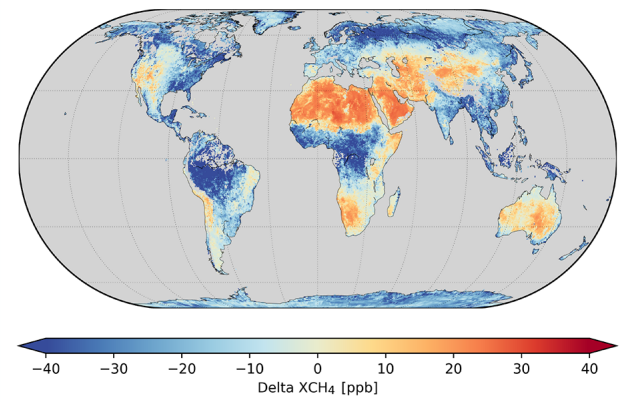

(c)

Figure 5. (a) Global TROPOMI $\mathrm{XCH}_{4}$ distribution before correction, (b) after correction and (c) their difference $\left(\mathrm{XCH}_{4}-\mathrm{XCH}_{4}^{\text {corr }}\right)$ for 2019 averaged in a cylindrical equal-area grid with $0.3^{\circ} \times 0.5^{\circ}$ resolution at the Equator.

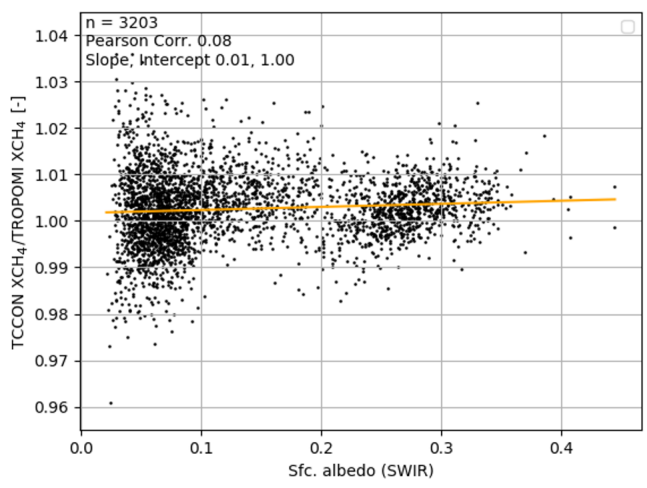

(a)

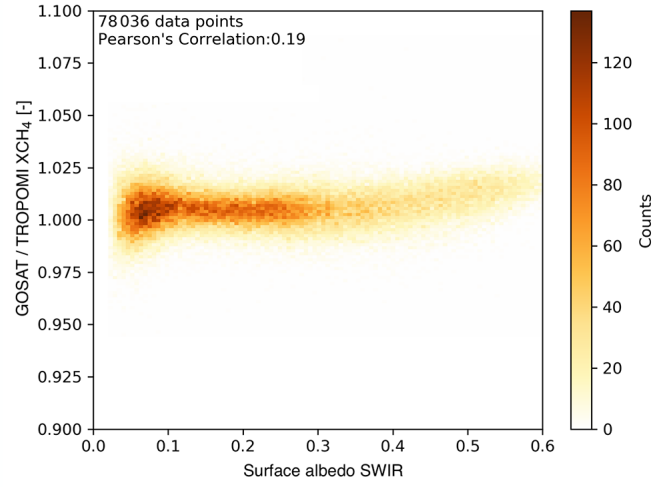

(b)

Figure 6. Ratio of daily $\mathrm{XCH}_{4}$ measurements by (a) TCCON and TROPOMI and (b) GOSAT and TROPOMI as a function of retrieved surface albedo in the SWIR spectral range. Data for the period 1 December 2018-31 December 2019 are shown.

the SWIR together with high surface albedo in the NIR indicates the presence of snow, which is highly correlated with the seasonality in the bias in East Trout Lake and Sodankylä, seasonality that is more pronounced in 2019 than 2018. The seasonal bias is also correlated with high hydrogen fluoride (HF) and low $\mathrm{H}_{2} \mathrm{O}$ concentrations (not shown). High HF concentrations are an indication of the influence of the vortex in a specific location, as HF is mostly found in the stratosphere; HF together with the contrast between surface albedo retrieved in the SWIR and NIR spectral ranges can be used as a proxy to identify the presence of snow and dry air from dynamic meteorological situations at high latitudes.

The presence of snow at high-latitude stations shifts the focus to retrieval errors as the most probable cause of the seasonal bias between TCCON and TROPOMI rather than errors due to collocation or influence of the different priors. Scenes covered by snow are characterized by low spectrum intensity in the SWIR, so signal-to-noise ratio is a limiting factor. On the other hand, the high TROPOMI signal in the NIR suggests that the weighting of each band might not be optimal in the inversion. As the optical properties are differ- 

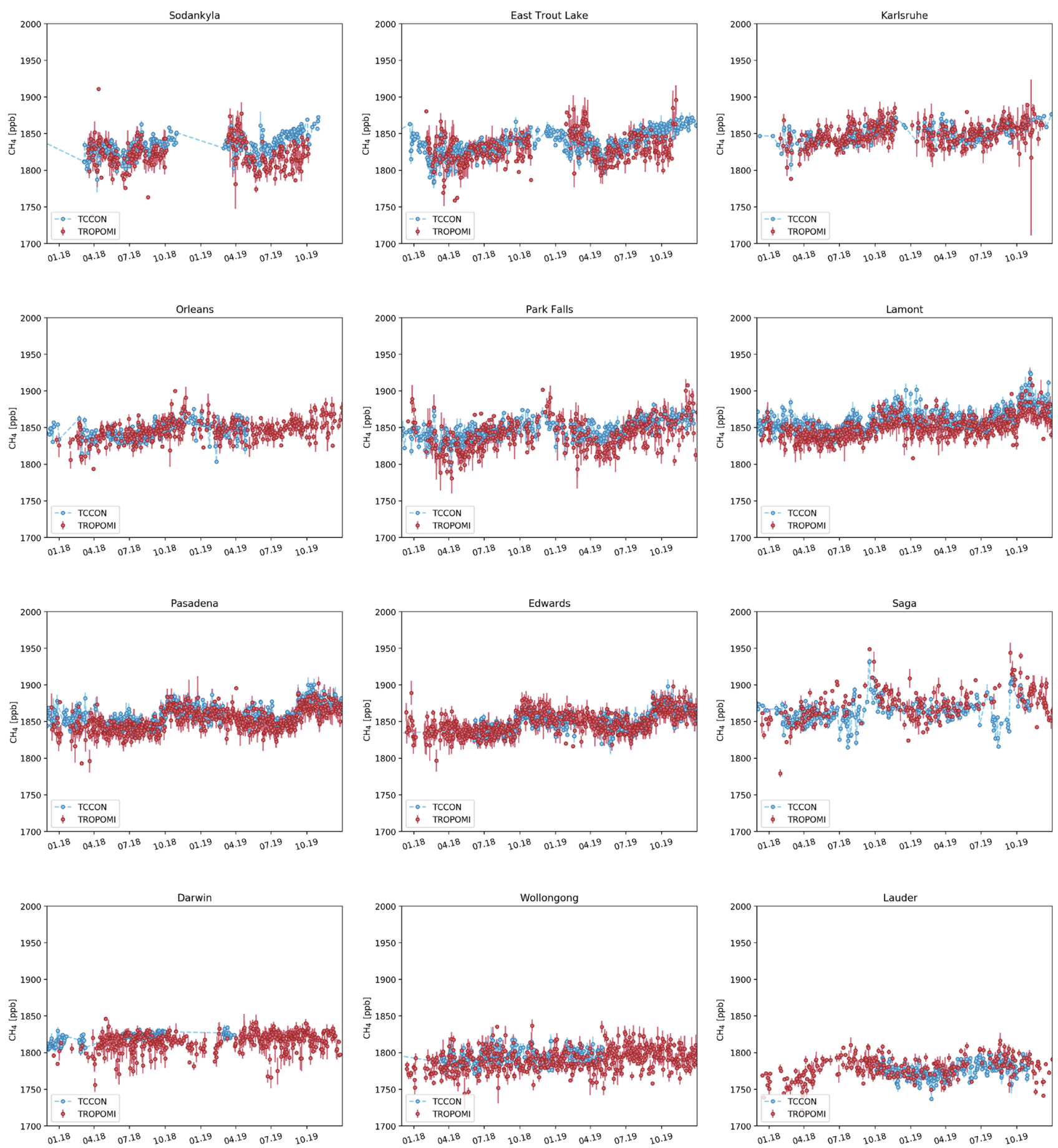

Figure 7. Time series of daily averaged $\mathrm{XCH}_{4}$ measurements from TROPOMI (red) and TCCON (blue) over the selected stations for the period 1 December 2018-31 December 2019. TROPOMI measurements around a circle of $300 \mathrm{~km}$ radius around each station have been selected for the comparison.

ent in the NIR and SWIR bands, errors in the quantification of light path modifications over snow-covered scenes can lead to an overestimation of retrieved $\mathrm{XCH}_{4}$. Furthermore, if $\mathrm{H}_{2} \mathrm{O}$ may compensate for any radiometric offset in the strong $\mathrm{CH}_{4}$ absorption bands, then in such dry conditions this would not be as effective in winter as in spring-autumn, causing the seasonality on the bias. A high bias in high latitudes correlated with $\mathrm{H}_{2} \mathrm{O}$ columns was also found in $\mathrm{H}_{2} \mathrm{O} / \mathrm{HDO}$ retrievals from TROPOMI by Schneider et al. (2020). Note that 

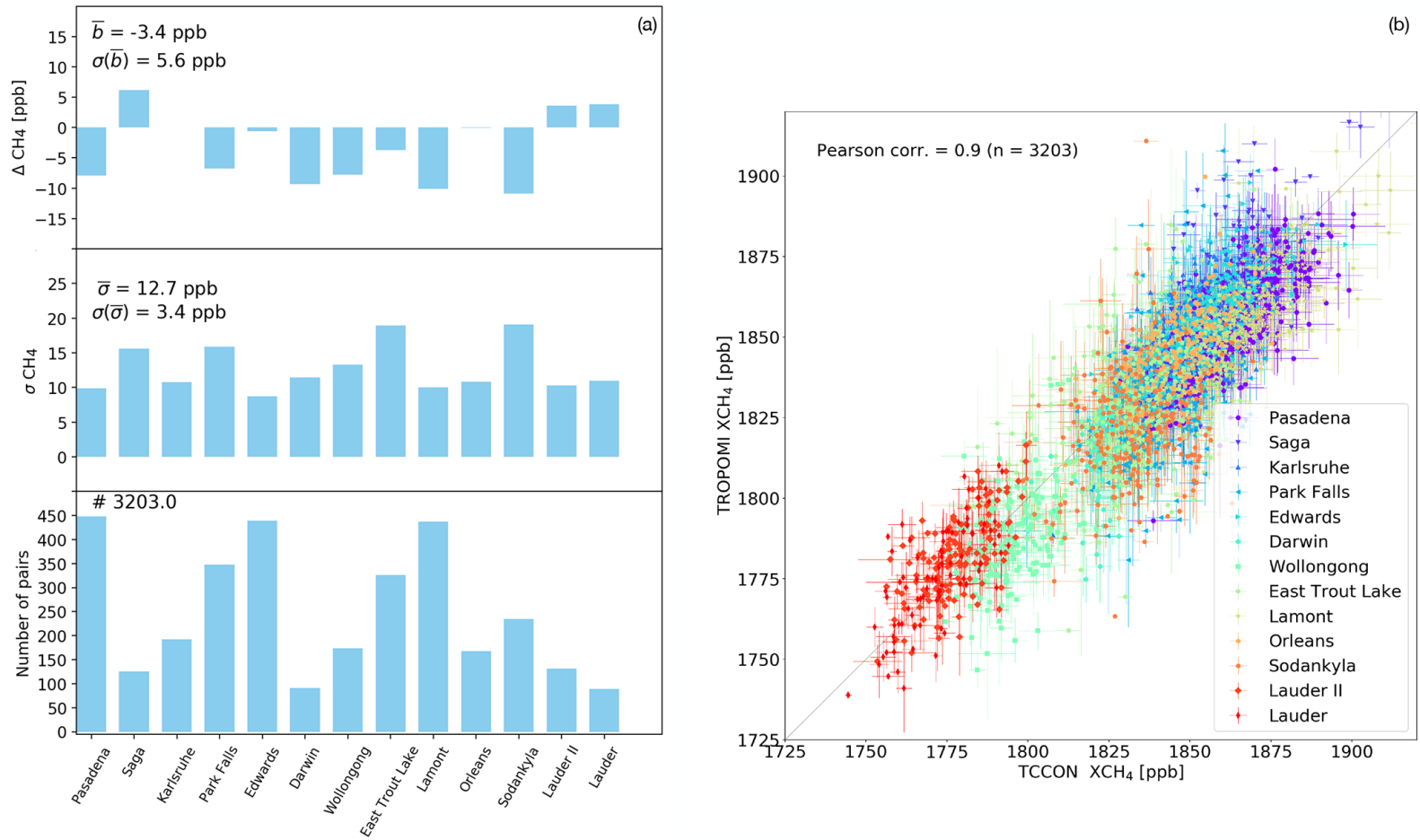

Figure 8. (a) Mean differences between TROPOMI and TCCON XCH $4\left(\Delta \mathrm{XCH}_{4}\right)$, the standard deviation of the differences $\left(\sigma \sigma_{\mathrm{XCH}}\right)$ and the

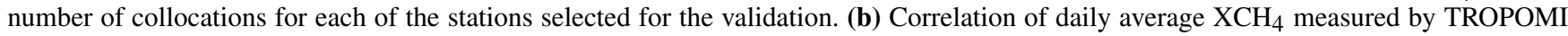
and TCCON for all the stations.

Table 3. Overview of the validation results of TROPOMI $\mathrm{XCH}_{4}$ with measurements from TCCON at selected stations. The table shows the number of collocations, mean bias and standard deviation for each station and the mean bias for all stations and the station-to-station variability (in ppb and in percentages between parenthesis). Results are shown for TROPOMI $\mathrm{XCH}_{4}$ with and without the albedo bias correction applied.

\begin{tabular}{|c|c|c|c|c|c|}
\hline \multirow[b]{2}{*}{ Site, country, lat., long. coord. } & \multirow[b]{2}{*}{$\begin{array}{l}\text { No. of } \\
\text { points }\end{array}$} & \multicolumn{2}{|c|}{$\begin{array}{c}\text { Corrected TROPOMI } \\
\mathrm{XCH}_{4} \text { and TCCON }\end{array}$} & \multicolumn{2}{|c|}{$\begin{array}{c}\text { Uncorrected TROPOMI } \\
\mathrm{XCH}_{4} \text { and TCCON }\end{array}$} \\
\hline & & $\begin{array}{r}\text { Bias } \\
(\mathrm{ppb})(\%)\end{array}$ & $\begin{array}{l}\text { Standard } \\
\text { deviation } \\
(\mathrm{ppb})(\%)\end{array}$ & $\begin{array}{r}\text { Bias } \\
(\mathrm{ppb})(\%)\end{array}$ & $\begin{array}{r}\text { Standard } \\
\text { deviation } \\
(\mathrm{ppb})(\%)\end{array}$ \\
\hline Pasadena (USA) $(34.14,-118.13)$ & 399 & $-8.0(-0.4)$ & $9.8(0.5)$ & $0.6(0.03)$ & 9.3 \\
\hline Saga (Japan) $(33.24,130.29)$ & 117 & $6.2(0.3)$ & $15.6(0.8)$ & $-17.6(-0.9)$ & $13.0(0.7)$ \\
\hline Karlsruhe (Germany) $(49.1,8.44)$ & 196 & $0.02(0.0)$ & $10.8(0.6)$ & $-19.2(-1.0)$ & $10.1(0.5)$ \\
\hline Darwin (Australia) $(-12.46,130.93)$ & 93 & $-9.3(-0.5)$ & $11.4(0.6)$ & $-16.5(-0.9)$ & $11.8(0.7)$ \\
\hline Wollongong (Australia) $(-34.41,150.88)$ & 132 & $-7.8(-0.4)$ & $13.3(0.7)$ & $-19.6(-1.1)$ & $14.9(0.8)$ \\
\hline Lauder I (New Zealand) $(-45.04,169.68)$ & 99 & $3.6(0.2)$ & $10.3(0.6)$ & $-12.3(-0.7)$ & $10.4(0.6)$ \\
\hline Lauder II (New Zealand) $(-45.04,169.68)$ & 93 & $3.8(0.2)$ & $11.0(0.6)$ & $-11.8(-0.67)$ & $10.8(0.6)$ \\
\hline Park Falls (USA) $(45.94,-90.27)$ & 325 & $-6.8(-0.4)$ & $15.9(0.9)$ & $-29.3(-1.6)$ & $17.4(0.9)$ \\
\hline East Trout Lake (Canada) $(54.36,-104.99)$ & 315 & $-3.7(-0.2)$ & $19.0(1.0)$ & $-27.1(-1.5)$ & $21.4(1.2)$ \\
\hline Lamont (USA) $(36.6,-97.49)$ & 388 & $-10.1(-0.5)$ & $10.0(0.5)$ & $-19.6(-1.1)$ & $11.2(0.6)$ \\
\hline Orléans (France) $(47.97,2.11)$ & 139 & $-0.07(0.0)$ & $10.8(0.6)$ & $-16.0(-0.9)$ & $12.0(0.7)$ \\
\hline Edwards (USA) $(34.95,-117.88)$ & 373 & $-0.6(-0.03)$ & $8.7(0.5)$ & $7.1(0.4)$ & $8.8(0.5)$ \\
\hline Sodankylä (Finland) $(67.37,26.63)$ & 234 & $-10.9(-0.6)$ & $19.1(1.0)$ & $-39.4(-2.1)$ & $18.6(1.0)$ \\
\hline Mean bias, station-to-station variability & & $-3.4(-0.2)$ & $5.6(0.3)$ & $-17.0(-0.9)$ & $11.5(0.6)$ \\
\hline
\end{tabular}




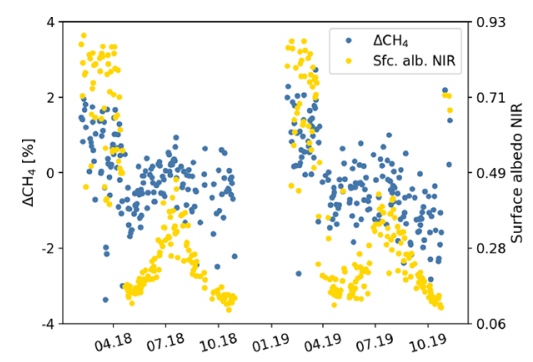

(a) East Trout Lake, NIR

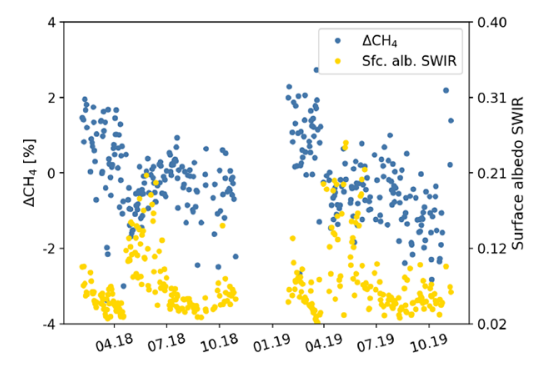

(b) East Trout Lake, SWIR

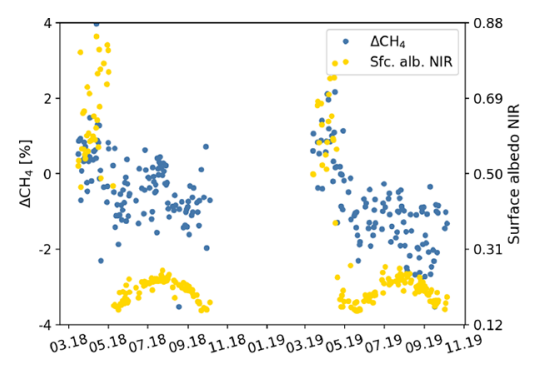

(c) Sodankylä, NIR

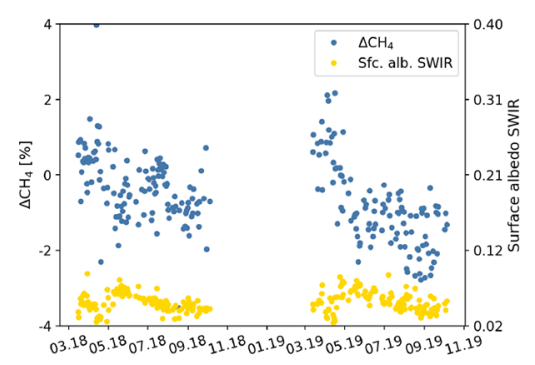

(d) Sodankylä, SWIR

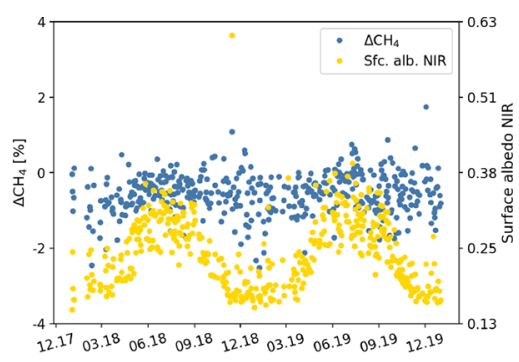

(e) Lamont, NIR

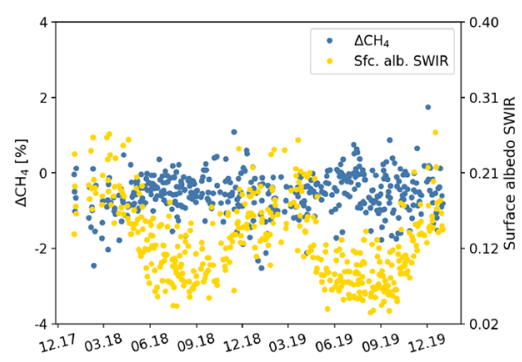

(f) Lamont, SWIR

Figure 9. Daily mean relative differences (blue, left axis) between TROPOMI and TCCON $\mathrm{XCH}_{4}\left(\Delta \mathrm{CH}_{4}\right)$ and surface albedo in the NIR (yellow, secondary axis, a, c, e) and surface albedo in the SWIR (yellow, secondary axis, b, d, f) at East Trout Lake (54.3 $\left.3^{\circ} \mathrm{N}\right)(\mathbf{a}, \mathbf{b})$, Sodankylä $\left(67.4^{\circ} \mathrm{N}\right)(\mathbf{c}, \mathbf{d})$ and Lamont $\left(36.6^{\circ} \mathrm{N}\right)(\mathbf{e}, \mathbf{f})$.

the seasonal bias is also present when $\mathrm{XCH}_{4}$ is retrieved using the spectroscopic databases discussed in Sect. 3.2.

To filter for scenes covered with snow or ice, Wunch et al. (2011b) introduced the so-called "blended albedo", which combines the surface albedo in the NIR and SWIR to be used as a filter. By applying it to Sodankylä and East Trout Lake, we found that a threshold value of 0.85 is optimal to remove these scenes that cause the seasonality on the bias. The influence of snow needs to be further investigated from the retrieval algorithm perspective, and it should be considered when interpreting the validation results and when analysing TROPOMI $\mathrm{XCH}_{4}$ data over snow-covered scenes, most prevalent at high latitudes.

\section{Comparison with GOSAT satellite}

We compare $\mathrm{XCH}_{4}$ retrieved from TROPOMI and GOSAT measurements for a period of 2 years (January 2018December 2019). The comparison yields a mean bias of $-10.3 \pm 16.8 \mathrm{ppb}(-0.6 \pm 0.9 \%)$ and a Pearson's correlation coefficient of 0.85 . The overall comparison yields a mean bias of $-12.5 \pm 14.9 \mathrm{ppb}$ if we use the GOSAT $\mathrm{XCH}_{4}$ product retrieved with the full-physics approach. Figure 10 shows TROPOMI and GOSAT $\mathrm{XCH}_{4}$ and their ratio averaged to a $2^{\circ} \times 2^{\circ}$ grid. Overall compared to GOSAT, TROPOMI underestimates $\mathrm{XCH}_{4}$, specially in the regions around the tropics in South America $(-0.6 \pm 0.8 \%)$ and in the African continent $(-0.9 \pm 0.8 \%)$. In Asia there is higher variability (up to $1 \%$ ) compared to other regions, with areas of underestimation as well as overestimation. The overall underestimation is stronger by about $2 \%$ in the non-corrected $\mathrm{XCH}_{4}$, reflecting that the albedo correction improves the TROPOMI $\mathrm{XCH}_{4}$ that is too low in areas where the surface albedo is low (e.g. forests around the Equator). For higher latitudes, the underestimation is less strong, and in some areas TROPOMI overestimates $\mathrm{XCH}_{4}$ compared to GOSAT (e.g. Greenland and Antarctica), in agreement with the high bias in $\mathrm{XCH}_{4}$ reported in the TCCON validation at East Trout Lake and Sodankylä.

The latitudinal distribution of $\mathrm{XCH}_{4}$ from TROPOMI, GOSAT and TROPOMI collocated with TCCON stations is shown in Fig. 11, summarizing the validation of TROPOMI $\mathrm{XCH}_{4}$ and showing the good agreement between the three datasets. Similar to Fig. 10, it shows that TROPOMI underestimates GOSAT at most latitudes but both overlap within the $\mathrm{XCH}_{4}$ variability. It also shows the shift to an overestimation at high latitudes where TROPOMI retrieves higher $\mathrm{XCH}_{4}$. This agrees with the conclusion that over snow TROPOMI $\mathrm{XCH}_{4}$ is too high, and although this distribution resembles the latitudinal distribution of $\mathrm{XCH}_{4}$ shown in Fig. 1, it cannot be attributed to the selection of the spectroscopic database.

\section{Conclusions}

We have presented several improvements that have been implemented in the retrieval of $\mathrm{XCH}_{4}$ from TROPOMI mea- 

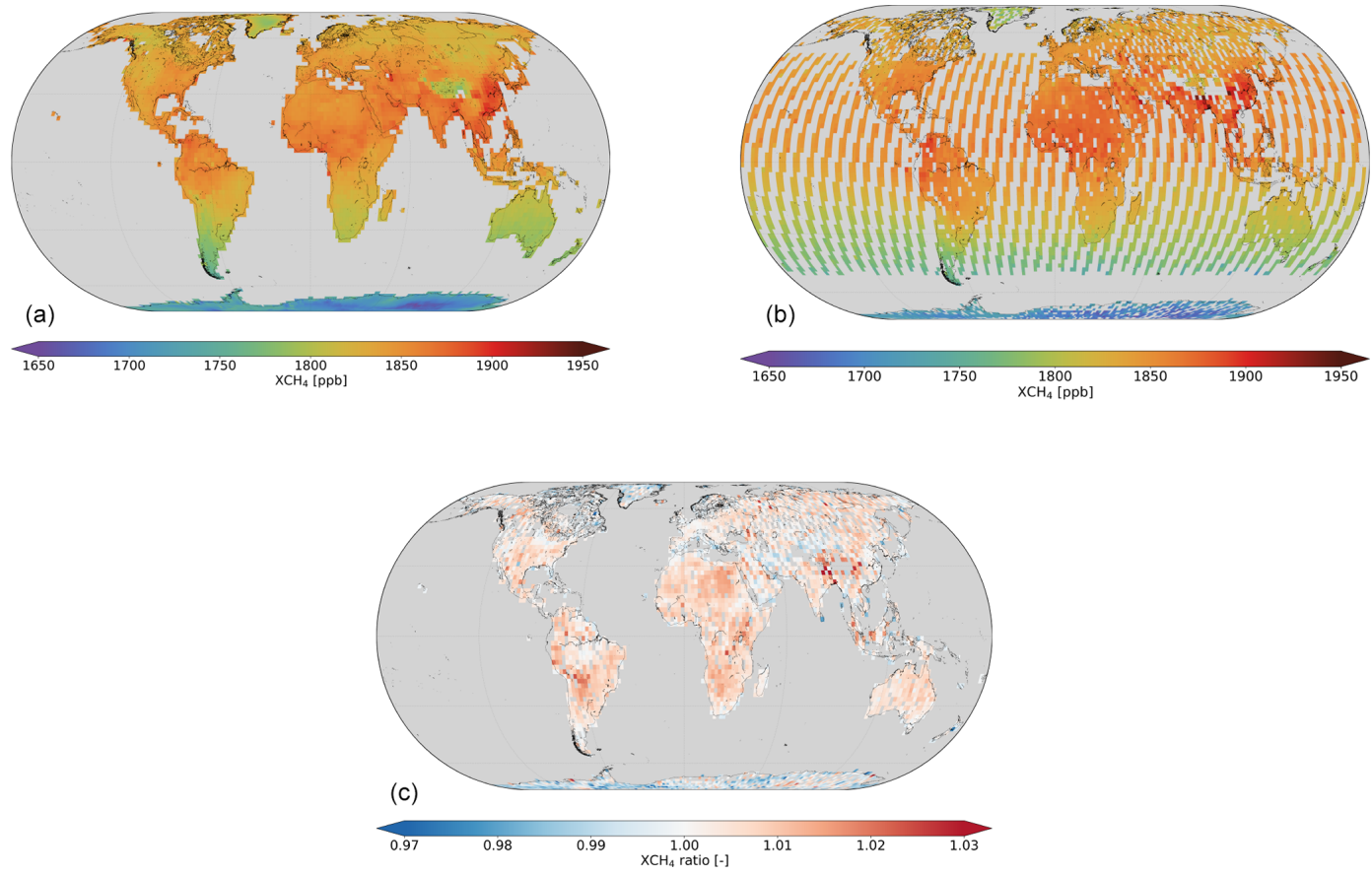

Figure 10. Global distribution of $\mathrm{XCH}_{4}$ measured by (a) TROPOMI and (b) GOSAT and (c) the ratio of GOSAT to TROPOMI XCH4 . Daily collocations are averaged to a $2^{\circ} \times 2^{\circ}$ grid for the period 1 January 2018-31 December 2019 .

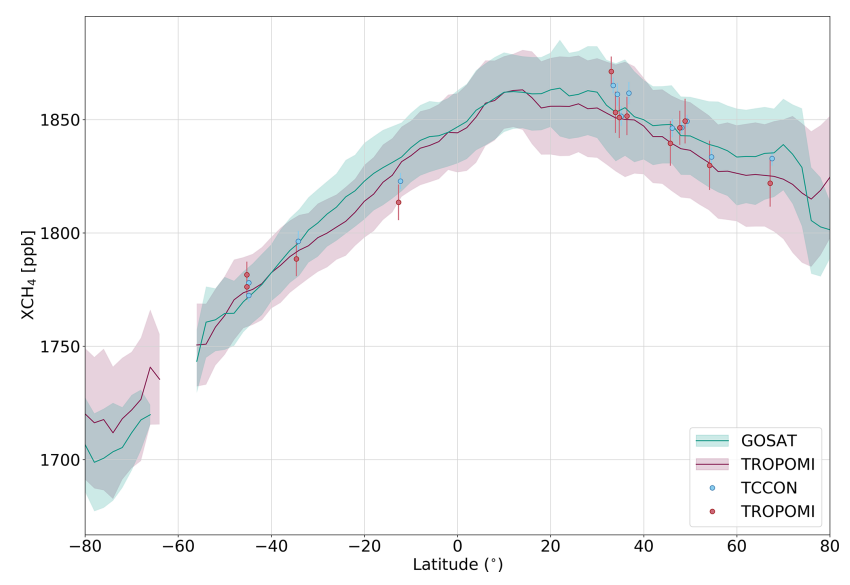

Figure 11. Latitudinal distribution of $\mathrm{XCH}_{4}$ measured by TROPOMI and GOSAT and the TROPOMI and TCCON collocations over the selected stations for validation in Sect. 4. The shaded bands indicate the scatter (i.e. $1 \sigma$ standard deviation) around the mean.

surements in the NIR and SWIR spectral range. Now that TROPOMI has been measuring for more than 2 years, the amount of data allows for the implementation of a series of updates that were not previously possible without the use of any reference data (i.e. regularization scheme and an a posteriori correction derived using only TROPOMI $\mathrm{XCH}_{4}$ data).

The regularization scheme with constant regularization parameters stabilizes the retrieval and yields less scatter in the TROPOMI $\mathrm{XCH}_{4}$ data compared to the operational data product (version 1.2.0; Hu et al., 2016). We have investigated the effect of the horizontal resolution of the surface elevation database by replacing GMTED2010 S5P with the SRTM $15^{\prime \prime}$ database, relevant in the $\mathrm{XCH}_{4}$ retrieval for which accurate knowledge of surface pressure is necessary. The higher resolution database results in a more realistic representation of surface altitude, particularly for mountainous regions and places with rough surfaces, where differences in surface pressure above $5 \mathrm{hPa}$ result in retrieved $\mathrm{XCH}_{4}$ that varies up to $10 \mathrm{ppb}$ for specific scenes.

We have tested three state-of-the-art spectroscopic databases (HITRAN 2008 with updates from Scheepmaker et al., 2013, HITRAN 2016 and SEOM-IAS). Using the SEOM-IAS database results in the best spectral fitting quality parameters in the retrieved $\mathrm{XCH}_{4}$. Each of the different spectroscopic databases introduces a bias in the distribution of $\mathrm{XCH}_{4}$ with respect to each other, but there is not any additional bias (e.g. latitudinal, albedo bias) that could point to the fitness for purpose of any of the databases. In view of the best fitting results, we decided to use the SEOMIAS database, which was derived specifically for TROPOMI. However, there is a need for a thorough and detailed analysis of these databases, focusing on the different absorbers that are relevant in the $\mathrm{CH}_{4}$ absorption bands to learn about the underlying processes that are driving the overall bias.

One of the most relevant updates is the implementation of an a posteriori correction that is fully independent of any reference data. We have derived a correction for the bias depen- 
dence on albedo using only TROPOMI $\mathrm{XCH}_{4}$ data. This has been possible due to the high resolution of TROPOMI and its global coverage. We select regions around the globe which cover different albedo ranges and dependencies to estimate the albedo bias. The new correction is more accurate than the regular polynomial fit for the strong $\mathrm{XCH}_{4}$ underestimation at low surface albedo scenes and also corrects for the positive bias in scenes with high surface albedo. After applying the correction, the albedo dependence in the TROPOMI-GOSAT and TROPOMI-TCCON comparison is removed, which is an independent verification of the correction scheme. The change in $\mathrm{XCH}_{4}$ induced by the bias correction is in the range of $2 \%$, and although we attribute it mostly to unaccounted for light path modification due to scattering processes, Butz et al. (2012) predicted residual scattering errors to be mostly below $1 \%$, which suggests that other errors might exist, which needs to be further investigated.

The good agreement of TROPOMI $\mathrm{XCH}_{4}$ with TCCON $(-3.4 \pm 5.6 \mathrm{ppb})$ and GOSAT $(-10.3 \pm 16.8 \mathrm{ppb})$ highlights the high quality of the TROPOMI measurements. Low- and high-albedo scenes are the most challenging for the $\mathrm{XCH}_{4}$ retrieval algorithm, and although the a posteriori correction accounts for most of the bias, there is a need to further understand the underlying cause and whether it originates in the instrument or in the retrieval algorithm. Also the overestimation of $\mathrm{XCH}_{4}$ over snow-covered scenes requires further investigation from the retrieval algorithm perspective. With respect to the validation, additional sites would be beneficial to cover the under-sampled regions and conditions. The network is currently limited to relatively low-albedo values, so there is a lack of reference data for high-albedo scenes, particularly around the Equator. Furthermore, there is a clear imbalance between the number of stations in the Northern and Southern Hemisphere, as well as a lack of stations below $45^{\circ} \mathrm{S}$. This is not only relevant for a complete validation of current and future satellite instruments, but also to have a complete global network to monitor concentrations of $\mathrm{CH}_{4}$ in the atmosphere. 


\section{Appendix A: Filtering criteria}

Table A1. Overview of the filters applied to ensure high-quality TROPOMI $\mathrm{XCH}_{4}$ retrievals.

\begin{tabular}{|c|c|}
\hline Parameter & Range \\
\hline Cloud fraction* from VIIRS inner field of view (IFOV) & $<0.001$ \\
\hline $\begin{array}{l}\text { Cloud fraction* from VIIRS outer field of view (OFOV) (up- } \\
\text { scaled FOV by } 10 \%, 50 \% \text { and } 100 \%)(\text { OFOVa, b, c) }\end{array}$ & $<0.001$ \\
\hline $\begin{array}{l}\text { Ratio of } \mathrm{XCH}_{4} \text { retrieved from strong and weak absorption } \\
\text { bands with the non-scattering retrieval using H2016 cross- } \\
\text { sections }\end{array}$ & $0.85<x<1.15$ \\
\hline $\begin{array}{l}\text { Standard deviation of } \mathrm{XCH}_{4} \text { ratio within SWIR pixel plus } 8 \\
\text { neighbouring pixels }\end{array}$ & $<0.05$ \\
\hline Signal-to-noise ratio & $>50$ \\
\hline Precision (noise-related error) & $<10$ \\
\hline$\chi^{2}$ & $<100$ \\
\hline Retrieved aerosol optical thickness (AOT) (SWIR) & $<0.1$ \\
\hline Surface albedo & $>0.02$ \\
\hline Solar zenith angle $\left(^{\circ}\right)$ & $<70$ \\
\hline Viewing zenith angle $\left(^{\circ}\right)$ & $<60$ \\
\hline $\begin{array}{l}\text { Terrain roughness }(\mathrm{m}) \text { standard deviation of surface elevation } \\
\text { within ground pixel }\end{array}$ & $<80$ \\
\hline
\end{tabular}

* Cloud fraction defined as the fraction of VIIRS pixels classified as confidently clear sky. 
Appendix B: Regions selected for the a posteriori correction

The regions selected to estimate the a posteriori correction are shown in Fig. B1.
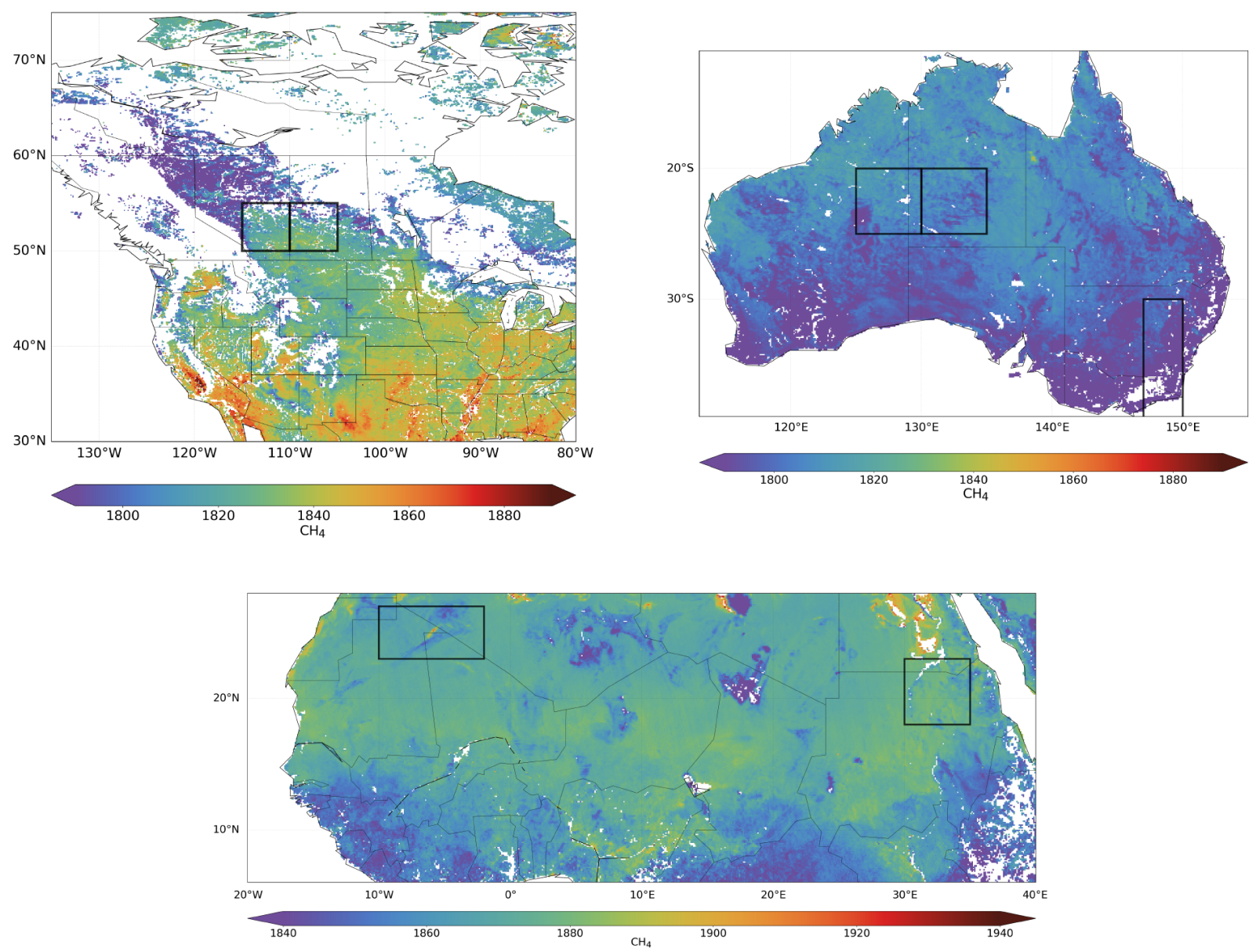

Figure B1. Black boxes over North Africa, Australia and Canada correspond to the different regions selected to estimate the a posteriori correction (see Sect. 3.4). Global distribution of $\mathrm{XCH}_{4}$ averaged to a $0.1^{\circ} \times 0.1^{\circ}$ grid for the period 1 January 2018-31 December 2019. 
Data availability. The SRON S5P-RemoTeC scientific TROPOMI CH4 dataset from this study is available for download at https://doi.org/10.5281/zenodo.4447228 (Lorente et al., 2021) or at https://ftp.sron.nl/open-access-data-2/TROPOMI/tropomi/ ch4/14_14_Lorente_et_al_2020_AMTD/ (last access: 27 January 2021). TCCON data are available from the TCCON Data Archive: Total Carbon Column Observing Network (TCCON), available at https://tccondata.org/ (last access: 12 January 2021).

Author contributions. AL, TB, OH, JdB, AS, AB and JL provided the TROPOMI $\mathrm{CH}_{4}$ retrieval and data analysis. The TCCON partners provided the validation datasets. AL wrote the original draft with input from TB and JL. All authors discussed the results and reviewed and edited the paper.

Competing interests. The authors declare that they have no conflict of interest.

Disclaimer. The presented work has been performed in the frame of Sentinel-5 Precursor Validation Team (S5PVT) or Level 1/Level 2 Product Working Group activities. Results are based on preliminary (not fully calibrated or validated) Sentinel-5 Precursor data that will still change. The results are based on S5P L1B version 1 data. Plots and data contain modified Copernicus Sentinel data, processed by SRON.

Acknowledgements. The TROPOMI data processing was carried out on the Dutch National e-Infrastructure with the support of the SURF Cooperative.

Financial support. Funding through the TROPOMI national program from the NSO and Methane+ is acknowledged. Darwin and Wollongong TCCON sites are funded by the Australian Research Council (DP140101552, DP160101598, LE0668470) and NASA (NAG5-12247, NNG05-GD07G). Nicholas M. Deutscher is supported by an ARC Future Fellowship (FT180100327).

Review statement. This paper was edited by Dominik Brunner and reviewed by two anonymous referees.

\section{References}

Aben, I., Hasekamp, O., and Hartmann, W.: Uncertainties in the space-based measurements of $\mathrm{CO}_{2}$ columns due to scattering in the Earth's atmosphere, J. Quant. Spectrosc. Ra., 104, 450-459, https://doi.org/10.1016/j.jqsrt.2006.09.013, 2007.

Barré, J., Aben, I., Agustí-Panareda, A., Balsamo, G., Bousserez, N., Dueben, P., Engelen, R., Inness, A., Lorente, A., McNorton, J., Peuch, V.-H., Radnoti, G., and Ribas, R.: Systematic detection of local $\mathrm{CH}_{4}$ emissions anomalies combining satellite measurements and high-resolution forecasts, Atmos. Chem. Phys. Dis- cuss. [preprint], https://doi.org/10.5194/acp-2020-550, in review, 2020.

Birk, M., Wagner, G., Loos, J., Wilzewski, J., Mondelain, D., Campargue, A., Hase, F., Orphal, J., Perrin, A., Tran, H., Daumont, L., Rotger-Languereau, M., Bigazzi, A., and Zehner, C.: Methane and water spectroscopic database for TROPOMI Sentinel 5 Precursor in the $2.3 \mu \mathrm{m}$ region, vol. 19, p. 4652, EGU General Assembly, 2017.

Borsdorff, T., aan de Brugh, J., Schneider, A., Lorente, A., Birk, M., Wagner, G., Kivi, R., Hase, F., Feist, D. G., Sussmann, R., Rettinger, M., Wunch, D., Warneke, T., and Landgraf, J.: Improving the TROPOMI CO data product: update of the spectroscopic database and destriping of single orbits, Atmos. Meas. Tech., 12, 5443-5455, https://doi.org/10.5194/amt-12-5443-2019, 2019.

Buchwitz, M., Reuter, M., Schneising, O., Hewson, W., Detmers, R. G., Boesch, H., Hasekamp, O., Aben, I., Bovensmann, H., Burrows, J., Butz, A., Chevallier, F., Dils, B., Frankenberg, C., Heymann, J., Lichtenberg, G., De Mazière, M., Notholt, J., Parker, R., Warneke, T., Zehner, C., Griffith, D. W. T., Deutscher, N., Kuze, A., Suto, H., and Wunch, D.: Global satellite observations of column-averaged carbon dioxide and methane: The GHG-CCI $\mathrm{XCO}_{2}$ and $\mathrm{XCH}_{4} \mathrm{CRDP} 3$ data set, Remote Sens. Environ., 203, 276-295, https://doi.org/10.1016/j.rse.2016.12.027, 2017.

Buchwitz, M., Aben, I., Armante, R., Boesch, H., Crevoisier, C., Di Noia, A., Hasekamp, O. P., Reuter, M., Schneising-Weigel, O., and Wu, L.: Algorithm Theoretical Basis Document (ATBD) - Main document for Greenhouse Gas (GHG: $\mathrm{CO}_{2}$ and $\mathrm{CH}_{4}$ ) data set CDR 3 (2003-2018), C3S project, 2019.

Butz, A., Guerlet, S., Hasekamp, O., Schepers, D., Galli, A., Aben, I., Frankenberg, C., Hartmann, J.-M., Tran, H., Kuze, A., Keppel-Aleks, G., Toon, G., Wunch, D., Wennberg, P., Deutscher, N., Griffith, D., Macatangay, R., Messerschmidt, J., Notholt, J., and Warneke, T.: Toward accurate $\mathrm{CO}_{2}$ and $\mathrm{CH}_{4}$ observations from GOSAT, Geophys. Res. Lett., 38, 14, https://doi.org/10.1029/2011GL047888, 2011.

Butz, A., Galli, A., Hasekamp, O., Landgraf, J., Tol, P., and Aben, I.: TROPOMI aboard Sentinel-5 Precursor: Prospective performance of $\mathrm{CH}_{4}$ retrievals for aerosol and cirrus loaded atmospheres, Remote Sens. Environ., 120, 267-276, https://doi.org/10.1016/j.rse.2011.05.030, 2012.

Frankenberg, C., Meirink, J. F., van Weele, M., Platt, U., and Wagner, T.: Assessing Methane Emissions from Global Space-Borne Observations, Science, 308, 1010-1014, https://doi.org/10.1126/science.1106644, 2005.

Gordon, I., Rothman, L., Hill, C., Kochanov, R., Tan, Y., Bernath, P., Birk, M., Boudon, V., Campargue, A., Chance, K., Drouin, B., Flaud, J.-M., Gamache, R., Hodges, J., Jacquemart, D., Perevalov, V., Perrin, A., Shine, K., Smith, M.-A., Tennyson, J., Toon, G., Tran, H., Tyuterev, V., Barbe, A., Császár, A., Devi, V., Furtenbacher, T., Harrison, J., Hartmann, J.-M., Jolly, A., Johnson, T., Karman, T., Kleiner, I., Kyuberis, A., Loos, J., Lyulin, O., Massie, S., Mikhailenko, S., MoazzenAhmadi, N., Müller, H., Naumenko, O., Nikitin, A., Polyansky, O., Rey, M., Rotger, M., Sharpe, S., Sung, K., Starikova, E., Tashkun, S., Auwera, J. V., Wagner, G., Wilzewski, J., Wcisło, P., Yu, S., and Zak, E.: The HITRAN 2016 molecular spectroscopic database, J. Quant. Spectrosc. Ra., 203, 3-69, https://doi.org/10.1016/j.jqsrt.2017.06.038, 2017. 
Griffith, D. W. T., Deutscher, N. M., Velazco, V. A., Wennberg, P. O., Yavin, Y., Keppel-Aleks, G., Washenfelder, R. A., Toon, G. C., Blavier, J.-F., Paton-Walsh, C., Jones, N. B., Kettlewell, G. C., Connor, B. J., Macatangay, R. C., Roehl, C., Ryczek, M., Glowacki, J., Culgan, T., and Bryant, G. W.: TCCON data from Darwin (AU), Release GGG2014.R0, https://doi.org/10.14291/tccon.ggg2014.darwin01.r0/1149290, 2017a.

Griffith, D. W. T., Velazco, V. A., Deutscher, N. M., Paton-Walsh, C., Jones, N. B., Wilson, S. R., Macatangay, R. C., Kettlewell, G. C., Buchholz, R. R., and Riggenbach, M.: TCCON data from Wollongong (AU), Release GGG2014.R0, https://doi.org/ 10.14291/tccon.ggg2014.wollongong01.r0/1149291, 2017b.

Guerlet, S., Butz, A., Schepers, D., Basu, S., Hasekamp, O. P., Kuze, A., Yokota, T., Blavier, J., Deutscher, N. M., Griffith, D. W., Hase, F., Kyro, E., Morino, I., Sherlock, V., Sussmann, R., Galli, A., and Aben, I.: Impact of aerosol and thin cirrus on retrieving and validating $\mathrm{XCO}_{2}$ from GOSAT shortwave infrared measurements, J. Geophys. Res.-Atmos., 118, 4887-4905, https://doi.org/10.1002/jgrd.50332, 2013.

Hansen, P.: Rank-Deficient and Discrete Ill-Posed Problems: Numerical Aspects of Linear Inversion, Mathematical Modeling and Computation, Society for Industrial and Applied Mathematics, 263 pp., https://doi.org/10.1137/1.9780898719697, 1998.

Hase, F., Blumenstock, T., Dohe, S., Groß, J., and Kiel, M.: TCCON data from Karlsruhe (DE), Release GGG2014.R0, https://doi.org/10.14291/tccon.ggg2014.karlsruhe01.r0/1149270, 2017.

Hasekamp, O., Lorente, A., Hu, H., Butz, A., aan de Brugh, J., and Landgraf, J.: Algorithm Theoretical Baseline Document for Sentinel-5 Precursor methane retrieval, available at: http://www.tropomi.eu/documents/atbd/ (last access: 11 January 2021), 2019.

Hu, H., Hasekamp, O., Butz, A., Galli, A., Landgraf, J., Aan de Brugh, J., Borsdorff, T., Scheepmaker, R., and Aben, I.: The operational methane retrieval algorithm for TROPOMI, Atmos. Meas. Tech., 9, 5423-5440, https://doi.org/10.5194/amt-9-54232016, 2016.

Hu, H., Landgraf, J., Detmers, R., Borsdorff, T., Aan de Brugh, J., Aben, I., Butz, A., and Hasekamp, O.: Toward Global Mapping of Methane With TROPOMI: First Results and Intersatellite Comparison to GOSAT, Geophys. Res. Lett., 45, 3682-3689, https://doi.org/10.1002/2018GL077259, 2018.

Inoue, M., Morino, I., Uchino, O., Nakatsuru, T., Yoshida, Y., Yokota, T., Wunch, D., Wennberg, P. O., Roehl, C. M., Griffith, D. W. T., Velazco, V. A., Deutscher, N. M., Warneke, T., Notholt, J., Robinson, J., Sherlock, V., Hase, F., Blumenstock, T., Rettinger, M., Sussmann, R., Kyrö, E., Kivi, R., Shiomi, K., Kawakami, S., De Mazière, M., Arnold, S. G., Feist, D. G., Barrow, E. A., Barney, J., Dubey, M., Schneider, M., Iraci, L. T., Podolske, J. R., Hillyard, P. W., Machida, T., Sawa, Y., Tsuboi, K., Matsueda, H., Sweeney, C., Tans, P. P., Andrews, A. E., Biraud, S. C., Fukuyama, Y., Pittman, J. V., Kort, E. A., and Tanaka, T.: Bias corrections of GOSAT SWIR $\mathrm{XCO}_{2}$ and $\mathrm{XCH}_{4}$ with TC$\mathrm{CON}$ data and their evaluation using aircraft measurement data, Atmos. Meas. Tech., 9, 3491-3512, https://doi.org/10.5194/amt9-3491-2016, 2016.

Iraci, L. T., Podolske, J. R., Hillyard, P. W., Roehl, C., Wennberg, P. O., Blavier, J.-F., Landeros, J., Allen, N., Wunch, D.,
Zavaleta, J., Quigley, E., Osterman, G. B., Albertson, R., Dunwoody, K., and Boyden, H.: TCCON data from Edwards (US), Release GGG2014.R1, https://doi.org/10.14291/TCCON. GGG2014.EDWARDS01.R1/1255068, 2016.

Kawakami, S., Ohyama, H., Arai, K., Okumura, H., Taura, C., Fukamachi, T., and Sakashita, M.: TCCON data from Saga (JP), Release GGG2014.R0, https://doi.org/10.14291/tccon.ggg2014.saga01.r0/1149283, 2017.

Kivi, R. and Heikkinen, P.: Fourier transform spectrometer measurements of column $\mathrm{CO}_{2}$ at Sodankylä, Finland, Geosci. Instrum. Method. Data Syst., 5, 271-279, https://doi.org/10.5194/gi-5-271-2016, 2016.

Kivi, R., Heikkinen, P., and Kyrö, E.: TCCON data from Sodankylä (FI), Release GGG2014.R0, https://doi.org/10.14291/ tccon.ggg2014.sodankyla01.r0/1149280, 2017.

Landgraf, J., Hasekamp, O. P., Box, M. A., and Trautmann, T.: A linearized radiative transfer model for ozone profile retrieval using the analytical forward-adjoint perturbation theory approach, J. Geophys. Res.-Atmos., 106, 27291-27305, https://doi.org/10.1029/2001JD000636, 2001.

Landgraf, J., Butz, A., Hasekamp, O., Hu, H., and aan de Brugh, J.: Sentinel 5 L2 Prototype Processors, Algorithm Theoretical Baseline Document: Methane Retrieval, SRON-ESA-S5L2PPATBD-001-v3.1-20190517-CH4, SRON Netherlands Institute for Space Research, Utrecht, the Netherlands, 2019.

Lorente, A., Borsdorff, T., aan de Brugh, J., Landgraf, J., and Hasekamp, O.: SRON S5P - RemoTeC scientific TROPOMI XCH4 dataset [Data set], Zenodo, https://doi.org/10.5281/zenodo.4447228, 2021.

Lunt, M. F., Palmer, P. I., Feng, L., Taylor, C. M., Boesch, H., and Parker, R. J.: An increase in methane emissions from tropical Africa between 2010 and 2016 inferred from satellite data, Atmos. Chem. Phys., 19, 14721-14740, https://doi.org/10.5194/acp-19-14721-2019, 2019.

Maasakkers, J. D., Jacob, D. J., Sulprizio, M. P., Scarpelli, T. R., Nesser, H., Sheng, J.-X., Zhang, Y., Hersher, M., Bloom, A. A., Bowman, K. W., Worden, J. R., Janssens-Maenhout, G., and Parker, R. J.: Global distribution of methane emissions, emission trends, and $\mathrm{OH}$ concentrations and trends inferred from an inversion of GOSAT satellite data for 2010-2015, Atmos. Chem. Phys., 19, 7859-7881, https://doi.org/10.5194/acp-197859-2019, 2019.

Miller, S. M., Michalak, A. M., Detmers, R. G., Hasekamp, O. P., Bruhwiler, L. M. P., and Schwietzke, S.: China's coal mine methane regulations have not curbed growing emissions, Nat. Commun., 10, 303, https://doi.org/10.1038/s41467-018-078917, 2019.

O’Dell, C. W., Eldering, A., Wennberg, P. O., Crisp, D., Gunson, M. R., Fisher, B., Frankenberg, C., Kiel, M., Lindqvist, H., Mandrake, L., Merrelli, A., Natraj, V., Nelson, R. R., Osterman, G. B., Payne, V. H., Taylor, T. E., Wunch, D., Drouin, B. J., Oyafuso, F., Chang, A., McDuffie, J., Smyth, M., Baker, D. F., Basu, S., Chevallier, F., Crowell, S. M. R., Feng, L., Palmer, P. I., Dubey, M., García, O. E., Griffith, D. W. T., Hase, F., Iraci, L. T., Kivi, R., Morino, I., Notholt, J., Ohyama, H., Petri, C., Roehl, C. M., Sha, M. K., Strong, K., Sussmann, R., Te, Y., Uchino, O., and Velazco, V. A.: Improved retrievals of carbon dioxide from Orbiting Carbon Observatory-2 with the version 8 ACOS algorithm, At- 
mos. Meas. Tech., 11, 6539-6576, https://doi.org/10.5194/amt11-6539-2018, 2018.

Pandey, S., Gautam, R., Houweling, S., van der Gon, H. D., Sadavarte, P., Borsdorff, T., Hasekamp, O., Landgraf, J., Tol, P., van Kempen, T., Hoogeveen, R., van Hees, R., Hamburg, S. P., Maasakkers, J. D., and Aben, I.: Satellite observations reveal extreme methane leakage from a natural gas well blowout, P. Natl. Acad. Sci., 116, 26376-26381, https://doi.org/10.1073/pnas.1908712116, 2019.

Pollard, D. F., Robinson, J., and Shiona, H.: TCCON data from Lauder (NZ), Release GGG2014.R0, https://doi.org/10.14291/TCCON.GGG2014.LAUDER03.R0, 2019.

Rothman, L., Gordon, I., Barbe, A., Benner, D., Bernath, P., Birk, M., Boudon, V., Brown, L., Campargue, A., Champion, J.-P., Chance, K., Coudert, L., Dana, V., Devi, V., Fally, S., Flaud, J.-M., Gamache, R., Goldman, A., Jacquemart, D., Kleiner, I., Lacome, N., Lafferty, W., Mandin, J.-Y., Massie, S., Mikhailenko, S., Miller, C., Moazzen-Ahmadi, N., Naumenko, O., Nikitin, A., Orphal, J., Perevalov, V., Perrin, A., Predoi-Cross, A., Rinsland, C., Rotger, M., Šimečková, M., Smith, M., Sung, K., Tashkun, S., Tennyson, J., Toth, R., Vandaele, A., and Auwera, J. V.: The HITRAN 2008 molecular spectroscopic database, J. Quant. Spectrosc. Ra., 110, 533-572, https://doi.org/10.1016/j.jqsrt.2009.02.013, 2009.

Saunois, M., Stavert, A. R., Poulter, B., Bousquet, P., Canadell, J. G., Jackson, R. B., Raymond, P. A., Dlugokencky, E. J., Houweling, S., Patra, P. K., Ciais, P., Arora, V. K., Bastviken, D., Bergamaschi, P., Blake, D. R., Brailsford, G., Bruhwiler, L., Carlson, K. M., Carrol, M., Castaldi, S., Chandra, N., Crevoisier, C., Crill, P. M., Covey, K., Curry, C. L., Etiope, G., Frankenberg, C., Gedney, N., Hegglin, M. I., Höglund-Isaksson, L., Hugelius, G., Ishizawa, M., Ito, A., Janssens-Maenhout, G., Jensen, K. M., Joos, F., Kleinen, T., Krummel, P. B., Langenfelds, R. L., Laruelle, G. G., Liu, L., Machida, T., Maksyutov, S., McDonald, K. C., McNorton, J., Miller, P. A., Melton, J. R., Morino, I., Müller, J., Murguia-Flores, F., Naik, V., Niwa, Y., Noce, S., O’Doherty, S., Parker, R. J., Peng, C., Peng, S., Peters, G. P., Prigent, C., Prinn, R., Ramonet, M., Regnier, P., Riley, W. J., Rosentreter, J. A., Segers, A., Simpson, I. J., Shi, H., Smith, S. J., Steele, L. P., Thornton, B. F., Tian, H., Tohjima, Y., Tubiello, F. N., Tsuruta, A., Viovy, N., Voulgarakis, A., Weber, T. S., van Weele, M., van der Werf, G. R., Weiss, R. F., Worthy, D., Wunch, D., Yin, Y., Yoshida, Y., Zhang, W., Zhang, Z., Zhao, Y., Zheng, B., Zhu, Q., Zhu, Q., and Zhuang, Q.: The Global Methane Budget 2000-2017, Earth Syst. Sci. Data, 12, 15611623, https://doi.org/10.5194/essd-12-1561-2020, 2020.

Scheepmaker, R. A., Frankenberg, C., Galli, A., Butz, A., Schrijver, H., Deutscher, N. M., Wunch, D., Warneke, T., Fally, S., and Aben, I.: Improved water vapour spectroscopy in the $4174-4300 \mathrm{~cm}^{-1}$ region and its impact on SCIAMACHY HDO/ $\mathrm{H}_{2} \mathrm{O}$ measurements, Atmos. Meas. Tech., 6, 879-894, https://doi.org/10.5194/amt-6-879-2013, 2013.

Schepers, D., Guerlet, S., Butz, A., Landgraf, J., Frankenberg, C., Hasekamp, O., Blavier, J.-F., Deutscher, N. M., Griffith, D. W. T., Hase, F., Kyro, E., Morino, I., Sherlock, V., Sussmann, R., and Aben, I.: Methane retrievals from Greenhouse Gases Observing Satellite (GOSAT) shortwave infrared measurements: Performance comparison of proxy and physics retrieval algorithms, J. Geophys. Res.-Atmos., 117, https://doi.org/10.1029/2012JD017549, 2012.

Schepers, D., aan de Brugh, J., Hahne, P., Butz, A., Hasekamp, O., and Landgraf, J.: LINTRAN v2.0: A linearised vector radiative transfer model for efficient simulation of satellite-born nadir-viewing reflection measurements of cloudy atmospheres, J. Quant. Spectrosc. Ra., 149, 347-359, 2014.

Schneider, A., Borsdorff, T., aan de Brugh, J., Aemisegger, F., Feist, D. G., Kivi, R., Hase, F., Schneider, M., and Landgraf, J.: First data set of $\mathrm{H}_{2} \mathrm{O} / \mathrm{HDO}$ columns from the Tropospheric Monitoring Instrument (TROPOMI), Atmos. Meas. Tech., 13, 85-100, https://doi.org/10.5194/amt-13-85-2020, 2020.

Schneising, O., Buchwitz, M., Reuter, M., Bovensmann, H., Burrows, J. P., Borsdorff, T., Deutscher, N. M., Feist, D. G., Griffith, D. W. T., Hase, F., Hermans, C., Iraci, L. T., Kivi, R., Landgraf, J., Morino, I., Notholt, J., Petri, C., Pollard, D. F., Roche, S., Shiomi, K., Strong, K., Sussmann, R., Velazco, V. A., Warneke, T., and Wunch, D.: A scientific algorithm to simultaneously retrieve carbon monoxide and methane from TROPOMI onboard Sentinel-5 Precursor, Atmos. Meas. Tech., 12, 67716802, https://doi.org/10.5194/amt-12-6771-2019, 2019.

Schneising, O., Buchwitz, M., Reuter, M., Vanselow, S., Bovensmann, H., and Burrows, J. P.: Remote sensing of methane leakage from natural gas and petroleum systems revisited, Atmos. Chem. Phys., 20, 9169-9182, https://doi.org/10.5194/acp-209169-2020, 2020.

Sherlock, V., Connor, B., Robinson, J., Shiona, H., Smale, D., and Pollard, D. F.: TCCON data from Lauder (NZ), 125HR, Release GGG2014.R0, https://doi.org/10.14291/tccon.ggg2014.lauder02.r0/1149298, 2017.

Turner, A. J., Frankenberg, C., and Kort, E. A.: Interpreting contemporary trends in atmospheric methane, P. Natl. Acad. Sci., 116, 2805-2813, https://doi.org/10.1073/pnas.1814297116, 2019.

Veefkind, J. P., Aben, I., McMullan, K., Förster, H., de Vries, J., Otter, G., Claas, J., Eskes, H., de Haan, J., Kleipool, Q., van Weele, M., Hasekamp, O., Hoogeveen, R., Landgraf, J., Snel, R., Tol, P., Ingmann, P., Voors, R., Kruizinga, B., Vink, R., Visser, H., and Levelt, P.: TROPOMI on the ESA Sentinel-5 Precursor: A GMES mission for global observations of the atmospheric composition for climate, air quality and ozone layer applications, Remote Sens. Environ., 120, 70-83, https://doi.org/10.1016/j.rse.2011.09.027, 2012.

Warneke, T., Messerschmidt, J., Notholt, J., Weinzierl, C., Deutscher, N. M., Petri, C., and Grupe, P.: TCCON data from Orléans (FR), Release GGG2014.R0, https://doi.org/10.14291/tccon.ggg2014.orleans01.r0/1149276, 2017.

Wennberg, P. O., Roehl, C. M., Wunch, D., Toon, G. C., Blavier, J.F., Washenfelder, R., Keppel-Aleks, G., Allen, N. T., and Ayers, J.: TCCON data from Park Falls (US), Release GGG2014.R1, https://doi.org/10.14291/tccon.ggg2014.parkfalls01.r1, 2017a.

Wennberg, P. O., Wunch, D., Roehl, C. M., Blavier, J.-F.v Toon, G. C., and Allen, N. T.: TCCON data from Lamont (US), Release GGG2014.R1, https://doi.org/10.14291/tccon.ggg2014.lamont01.r1/1255070, 2017b.

Wennberg, P. O., Wunch, D., Roehl, C. M., Blavier, J.-F., Toon, G. C., and Allen, N. T.: TCCON 
data from Caltech (US), Release GGG2014.R0, https://doi.org/10.14291/tccon.ggg2014.pasadena01.r0/1149162, $2017 \mathrm{c}$.

Wu, L., Hasekamp, O., Hu, H., Landgraf, J., Butz, A., aan de Brugh, J., Aben, I., Pollard, D. F., Griffith, D. W. T., Feist, D. G., Koshelev, D., Hase, F., Toon, G. C., Ohyama, H., Morino, I., Notholt, J., Shiomi, K., Iraci, L., Schneider, M., de Mazière, M., Sussmann, R., Kivi, R., Warneke, T., Goo, T.-Y., and Té, Y.: Carbon dioxide retrieval from OCO-2 satellite observations using the RemoTeC algorithm and validation with TCCON measurements, Atmos. Meas. Tech., 11, 3111-3130, https://doi.org/10.5194/amt-11-3111-2018, 2018.

Wunch, D., Toon, G. C., Blavier, J.-F. L., Washenfelder, R. A., Notholt, J., Connor, B. J., Griffith, D. W. T., Sherlock, V., and Wennberg, P. O.: The Total Carbon Column Observing Network, Philos. T. Roy. Soc. A, 369, 2087-2112, https://doi.org/10.1098/rsta.2010.0240, 2011a.

Wunch, D., Wennberg, P. O., Toon, G. C., Connor, B. J., Fisher, B., Osterman, G. B., Frankenberg, C., Mandrake, L., O'Dell, C., Ahonen, P., Biraud, S. C., Castano, R., Cressie, N., Crisp, D., Deutscher, N. M., Eldering, A., Fisher, M. L., Griffith, D. W. T., Gunson, M., Heikkinen, P., Keppel-Aleks, G., Kyrö, E., Lindenmaier, R., Macatangay, R., Mendonca, J., Messerschmidt, J., Miller, C. E., Morino, I., Notholt, J., Oyafuso, F. A., Rettinger, M., Robinson, J., Roehl, C. M., Salawitch, R. J., Sherlock, V., Strong, K., Sussmann, R., Tanaka, T., Thompson, D. R., Uchino, O., Warneke, T., and Wofsy, S. C.: A method for evaluating bias in global measurements of $\mathrm{CO}_{2}$ total columns from space, Atmos. Chem. Phys., 11, 12317-12337, https://doi.org/10.5194/acp-11-12317-2011, 2011 b.
Wunch, D., Mendonca, J., Colebatch, O., Allen, N. T., Blavier, J.-F., Roche, S., Hedelius, J.v Neufeld, G., Springett, S., Worthy, D., Kessler, R., and Strong, K.: TCCON data from East Trout Lake, SK (CA), Release GGG2014.R1, https://doi.org/10.14291/tccon.ggg2014.easttroutlake01.r1, 2017.

Zhang, Y., Gautam, R., Pandey, S., Omara, M., Maasakkers, J. D., Sadavarte, P., Lyon, D., Nesser, H., Sulprizio, M. P., Varon, D. J., Zhang, R., Houweling, S., Zavala-Araiza, D., Alvarez, R. A., Lorente, A., Hamburg, S. P., Aben, I., and Jacob, D. J.: Quantifying methane emissions from the largest oilproducing basin in the United States from space, Sci. Adv., 6, 17, https://doi.org/10.1126/sciadv.aaz5120, 2020. 